\title{
Análisis de las publicaciones de investigadores del Subsistema de la I nvestigación Científica de la Universidad Nacional Autónoma de México 1981-2003 ${ }^{1}$
}

\author{
J orge Gil Mendieta y Alejandro Arnulfo Ruiz León ${ }^{2}$ - Instituto de Investigaciones en \\ Matemáticas Aplicadas y en Sistemas (IIMAS-UNAM)
}

\section{Resumen}

Se presenta una visión general de las redes de académicos construidas por medio del análisis de sus artículos científicos, indizados por la empresa Thomson Reuters (antes ISI Thomson). Se presentan los resultados más importantes relacionados con la estructura de las colaboraciones científicas entre académicos de la UNAM, el Subsistema de la Investigación Científica (SIC) y diversas entidades académicas nacionales que no forman parte de ninguna entidad de la UNAM. Se analiza la interacción de las entidades académicas del Subsistema, así como las interacciones entre los diversos subsistemas: subsistema de la investigación científica (SIC), subsistema de humanidades (SH), subsistema de Facultades y Escuelas (SFE) y el correspondiente de la Secretaría General (SSG). La base de datos analizada comprende 71878 artículos de México, indizados por ISI Thomson, de los cuales $38 \%$ corresponden al SIC. Los artículos que contiene la base están fechados entre 1981 y 2003.

Palabras clave: redes académicas - artículos científicos - indizados - estructura ISI Thomson.

\begin{abstract}
A general academic networks view is presented. This network has been build from the author's interaction through their scientific papers, indexed by Thomson Reuters (previously ISI Thomson). Accent is place in the interaction of main academic subsystems: Scientific Research; Schools and Faculties; Humanities Research and General Secretary Office. The data base under analysis encompass 71878 papers with one Mexico's coauthor at least, all papers are indexed by ISI Thomson. Papers publication date goes from 1981 to 2003.
\end{abstract}

Key words: academic networks - scientific papers - indexed - structure ISI Thomson.

\section{I ntroducción}

En la literatura se encuentra una enorme cantidad de artículos sobre el análisis de publicaciones científicas de investigadores que trabajan en diversos campos del conocimiento. Por ejemplo citemos a E. Garfield ${ }^{3}$, creador de este campo de estudio en particular, uno de cuyos trabajos atrajo la atención del mundo científico el Genetics Citation Index, una de las primeras bases de datos que consideraba en su análisis 600 revistas publicadas desde 1961, proyecto aprobado por la National

\footnotetext{
${ }^{1}$ Este trabajo ha contado con el apoyo del IIMAS-UNAM, la Coordinación de la Investigación Científica y la Dirección General de Asuntos del Personal Académico (DGAPA-UNAM) a través del Proyecto PAPIIT IN-313905.

${ }^{2}$ Enviar correspondencia a: (Jorge Gil Mendieta jgil@servidor.unam.mx)

${ }^{3}$ Garfield, E. (Chairman Emeritus, ISI), "Systematic Serendipity: Finding the Undiscovered Answers to Science Questions", The Medical I gnorance Collaboratory University of Arizona Health Science Center, Tucson, Arizona, USA.
} 
REDES- Revista hispana para el análisis de redes sociales

Vol.17,\#1, diciembre 2009

http: //revista-redes.rediris.es

Science Fundation, cuyos resultados los distribuyó a 1,000 genetistas, logrando resultados muy importantes. En épocas recientes tenemos el trabajo de Katz y Martin $1997^{4}$ quienes escriben sobre el concepto de colaboración, su importancia y significado; demuestran que la publicación de artículos con coautores es un indicador parcial del concepto de colaboración. Newman 2001 ${ }^{5}$, investiga la estructura científica de las redes de colaboración de publicaciones reportadas en las bases de datos MEDLINE (investigación biomédica), Los Alamos e-printArchive (Física), y NCSTRL (ciencias de la computación) y demuestra que las colaboraciones forman "pequeños mundos". J. M. Russell 2004, nos habla sobre las comunicaciones científicas en el siglo XXI, de cómo comunican sus investigaciones los científicos en la época moderna; de cómo se han modificado los patrones de comunicación de resultados y el desarrollo de nuevas tecnologías de comunicación que ha propiciado cambios importantes en las grandes editoriales.

La base de datos de la empresa The Thomson Corporation (antes ISI), una de las principales fuentes de información de la publicación de artículos científicos indexados, clasifica en la actualidad los artículos de 20,075 revistas en todos los campos en la base ISI Web of Science. También en su base Esencial Science Indicators 1993-2003 encontramos la distribución del número de artículos y el número de citas relacionadas con los 22 campos de conocimiento en que clasifica los artículos que indexa. En la Gráfica 1 presentamos el número total de artículos y el número de citas que reciben los artículos, agrupados por cada campo y por cada país. E. Garfield ${ }^{6}$ escribió un artículo como resultado de una encuesta en la que preguntó a un grupo de investigadores: “¿Cuándo se debe citar un trabajo?”. Al final del experimento se generó una lista de quince razones principales para citar un trabajo; Garfield nos dice que, en primer lugar, se cita a los pioneros; enseguida, se les da crédito a los trabajos relacionados con el nuestro; en tercer lugar, se reconoce la metodología; a aquellos artículos que nos proporcionan una base general de información; a los que corrigen nuestro trabajo, entre otros. En general se citan los trabajos que nos proporcionan conocimiento de nuestro propio campo de estudio.

\footnotetext{
${ }^{4}$ Katz, J. S. and Martin, B. R., "What is research collaboration?", ESRC Center for Science. Technology, Energy and Environment Policy, Science Policy Research Unit, University of Sussex, Falmer, Brighton, BN1 9RF, UK.

${ }^{5}$ Newman, M. E. J., "The structure of scientific collaboration networks", PNAS, Vol. 98, no.2, pp. $404-$ 409, January 16, 2001.

${ }^{6}$ Garfield, E. “When to cite", Library Quaterly, Vol:66 (4), p.449-458, Octuber 1996.
} 
REDES- Revista hispana para el análisis de redes sociales

Vol.17,\#1, diciembre 2009

http: //revista-redes.rediris.es

Las citas que hacen los investigadores en sus artículos nos orientan para establecer la genealogía del conocimiento de los 22 campos en que ISI-Thomson los clasifica. Mediante la Gráfica 1 representamos la distribución de artículos y citas de más de cien países que aparecen a lo largo de una línea, en una gráfica log-log con una dispersión muy baja.

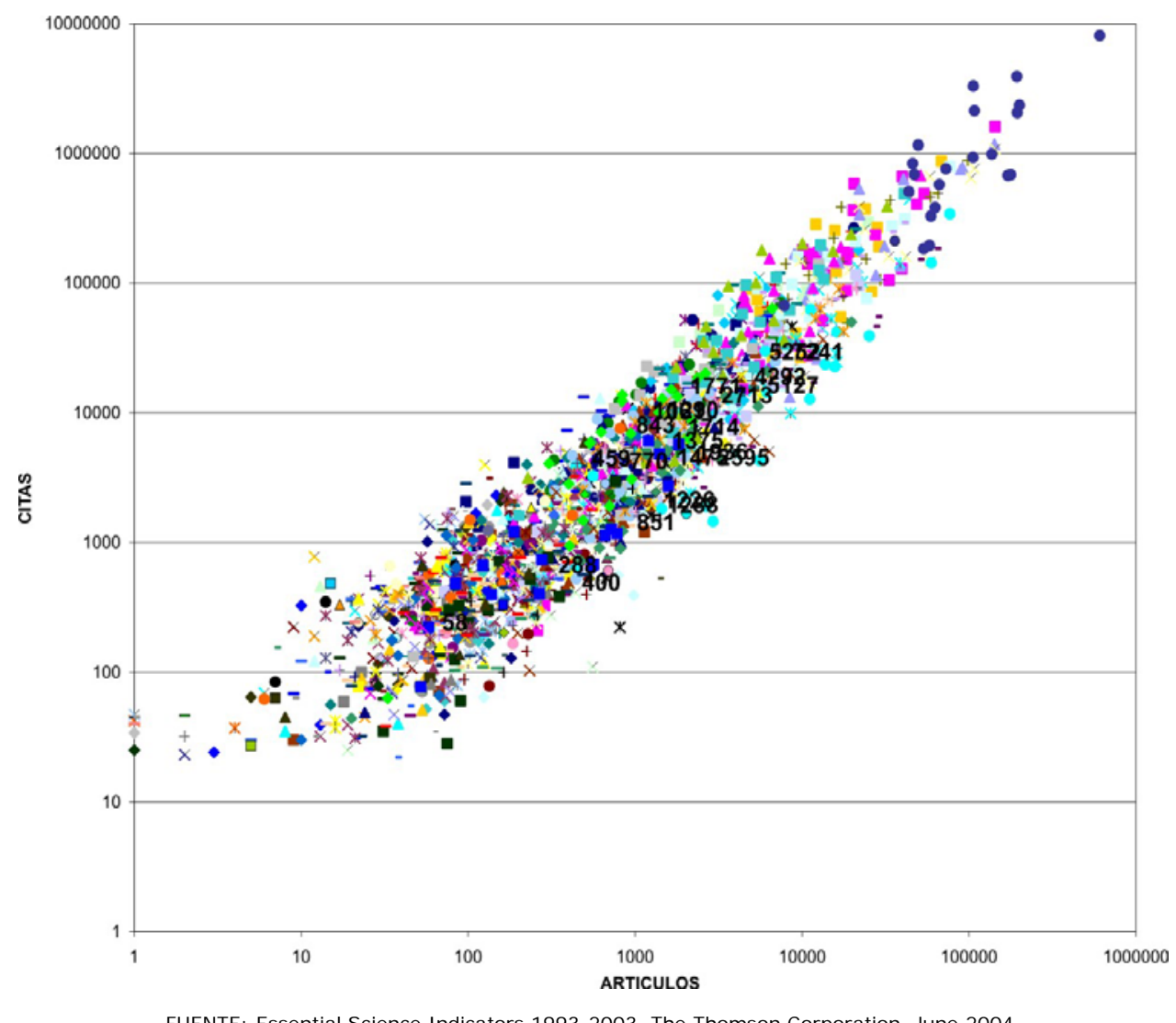

Gráfica 1. Número total de artículos y número total de citas por campo de conocimiento para más de cien países.

En el caso de nuestro país vemos en la Tabla 1 que la máxima productividad en México es en física con más de siete mil artículos y una cifra del orden de 300 mil citas, en una base de datos de 1993 a 2003. El campo menos citado es el que corresponde al multidisciplinario con menos de 100 artículos y una cifra del orden de 200 citas.

El promedio del número de citas de todos los campos es 4.64 citas por artículo, en una ventana de tiempo que va de 1993 a 2003.

Garfield ${ }^{7}$ menciona la importancia del desarrollo de la ciencia y de la tecnología y de la necesidad de contar con elementos para medir los avances de éstas y como

\footnotetext{
${ }^{7}$ Garfield, E. and Welljams-Dorof, A. Citation data: their use as quantitative indicators for science and technology evaluation and policy-making, Science \& Public Policy, 19(5) pp.321-327, October 1992.
} 
REDES- Revista hispana para el análisis de redes sociales

Vol.17, \#1, diciembre 2009

http: //revista-redes.rediris.es

instrumentos en la planeación estratégica de las empresas, las corporaciones y las universidades.

\begin{tabular}{|l|c|c|c|}
\hline \multicolumn{1}{|c|}{ MEXI CO } & ARTí CULOS & CITAS & C/ A \\
\hline PHYSICS & 7241 & 29258 & 4.04 \\
\hline CLINICAL MEDICINE & 5252 & 29202 & 5.56 \\
\hline PLANT_ANI MAL_SCIENCE & 5127 & 16237 & 3.16 \\
\hline CHEMISTRY & 4292 & 18898 & 4.40 \\
\hline BIOLOGY \& BIOCHEMISTRY & 2713 & 13478 & 4.96 \\
\hline ENGINEERING & 2595 & 4536 & 1.74 \\
\hline MATERIALS SCIENCE & 1936 & 4983 & 2.57 \\
\hline SPACE SCIENCE & 1771 & 15927 & 8.99 \\
\hline ENVIRONMENT_ECOLOGY & 1714 & 7701 & 4.49 \\
\hline AGRICULTURAL SCIENCES & 1475 & 4512 & 3.05 \\
\hline GEOSCIENCES & 1375 & 6014 & 4.37 \\
\hline NEUROSCIENCE \& BEHAVIOR & 1290 & 10356 & 8.02 \\
\hline MATHEMATICS & 1288 & 1935 & 1.50 \\
\hline SOCIAL SCIENCES, GENERAL & 1226 & 2110 & 1.72 \\
\hline MICROBIOLOGY & 1061 & 10261 & 9.67 \\
\hline PSYCHIATRY_PSYCHOLOGY & 851 & 1431 & 1.68 \\
\hline MOLECULAR BIOLOGY \& GENETICS & 843 & 8013 & 9.50 \\
\hline PHARMACOLOGY \& TOXICOLOGY & 770 & 4209 & 5.46 \\
\hline IMMUNOLOGY & 459 & 4424 & 9.63 \\
\hline COMPUTER SCIENCE & 400 & 487 & 1.21 \\
\hline ECONOMICS \& BUSINESS & 288 & 665 & 2.30 \\
\hline MULTIDISCIPLINARY & 58 & 243 & 4.19 \\
\hline SUbtOtales & 44025 & 168581 & 3.83 \\
\hline & & \\
\hline
\end{tabular}

FUENTE: Laboratorio de Redes, Departamento de Modelación Matemática de Sistemas Sociales, IIMAS-UNAM, 2005 con datos de Essential Science Indicators 1993-2003, The ThomsonCorporation, June $2004^{8}$

Tabla 1. Número total de artículos de México por campo.

En el este trabajo se presenta el análisis de la publicación de artículos en los que participan científicos mexicanos, en particular de los artículos de autores asociados a las diversas entidades del subsistema de la Investigación Científica de la Universidad Nacional Autónoma de México. Para tal propósito se tomó como fuente la base de datos National Citation Report México, julio de 2004 (NCRMEX), la base

\footnotetext{
“Pocos podrán discutir la propuesta de que la base científica y tecnológica son un elemento crítico en la fortaleza de la economía, de la estatura política y de la vitalidad cultural de un país. Los administradores del gobierno, los creadores de las políticas de ciencia y tecnología y los directivos de las universidades requieren de indicadores validos y confiables para una variedad de propósitos: por ejemplo, para medir la efectividad del gasto en investigación, identificar las áreas de excelencia, para fijar prioridades en su planeación estratégica, monitorear el avance de sus competidores y de sus colegas, y detectar especialidades emergentes y nuevas tecnologías para lograr un desarrollo acelerado"

${ }^{8}$ Laboratorio de Redes, Departamento de Modelación Matemática de Sistemas Sociales, Instituto de Investigaciones e Matemáticas Aplicadas y en Sistemas, Universidad Nacional Autónoma de México, lo abreviamos como: LAR-DMMSS-IIMAS-UNAM.
} 
REDES- Revista hispana para el análisis de redes sociales

Vol.17, \#1, diciembre 2009

http: //revista-redes.rediris.es

contiene información de artículos publicados en revistas internacionales indizadas por ISI-Thomson, del año de 1981 al 2003, y en los que han participado autores, al menos uno, afiliados a instituciones mexicanas. También se consultaron las siguientes bases: Journal Citation Reports (JCR2003) que proporciona información bibliográfica de más de 8400 revistas; y la base Essential Science Indicators (ESI2003), que proporciona información bibliográfica de más de 11591 revistas. Información clasificada en 22 campos. Así mismo se consultó la base Current Content de donde se adopto la clasificación de los artículos de acuerdo a siete áreas de conocimiento que agrupan a 130 categorías. Cabe señalar que por su naturaleza ciertos artículos han sido clasificados en más de una categoría e incluso en más de un área de conocimiento, por lo que el número total de artículos de todas las áreas no corresponde al número total de artículos que analizamos, de igual manera para el número total de artículos por categoría.

Uno de los problemas con los que nos topamos fue que la información sobre la asociación de los autores a la universidad a la que pertenecen es poco clara y precisa, hay una gran variedad de formas en que los investigadores hacen referencia a su entidad de origen; alguien hace referencia en primer lugar a su sección, grupo, departamento, unidad dentro de la universidad, la universidad y el país, y variantes sobre todas estas componentes de su entidad de origen, de tal suerte que las direcciones asociadas a la UNAM y al País se multiplican de forma complicada y que resumimos de la siguiente manera: el número de direcciones diferentes asociadas a la UNAM es del orden de 20,000. Esto nos llevó a que la UNAM estableciera normas para que los autores escriban el nombre de la Universidad de manera consistente en sus artículos, a saber iniciando por Universidad Nacional Autónoma de México, seguido del nombre de su entidad académica, departamento, dirección, código postal y país.

\section{México}

\section{Publicación total de artículos}

El número total de artículos indizados por ISI-Thomson con participación de investigadores afiliados a instituciones mexicanas, en el periodo bajo estudio, es de 71868. La UNAM participa en casi el 38\% de la producción de los artículos, el otro $62 \%$ lo realizan diversas instituciones, ver Gráfica 2.

\section{Publicación anual de artículos}

La publicación anual de artículos a nivel nacional presenta un incremento notorio y constante a partir del año de 1990 (Gráfica 3), antes de 1990 la tasa de crecimiento anual promedio nacional de artículos era de $2.9 \%$, la de la UNAM de 
REDES- Revista hispana para el análisis de redes sociales

Vol.17,\#1, diciembre 2009

http: //revista-redes.rediris.es

$6 \%$ y la de otras instituciones sin incluir a la UNAM del $1.22 \%$. Del año de 1990 al 2002 la tasa de crecimiento anual promedio nacional fue de 15\%, la de la UNAM del $10 \%$ y la de las diversas instituciones sin incluir a la UNAM de $11.6 \%$, lo que marca un despunte en la producción de artículos de otras entidades nacionales.

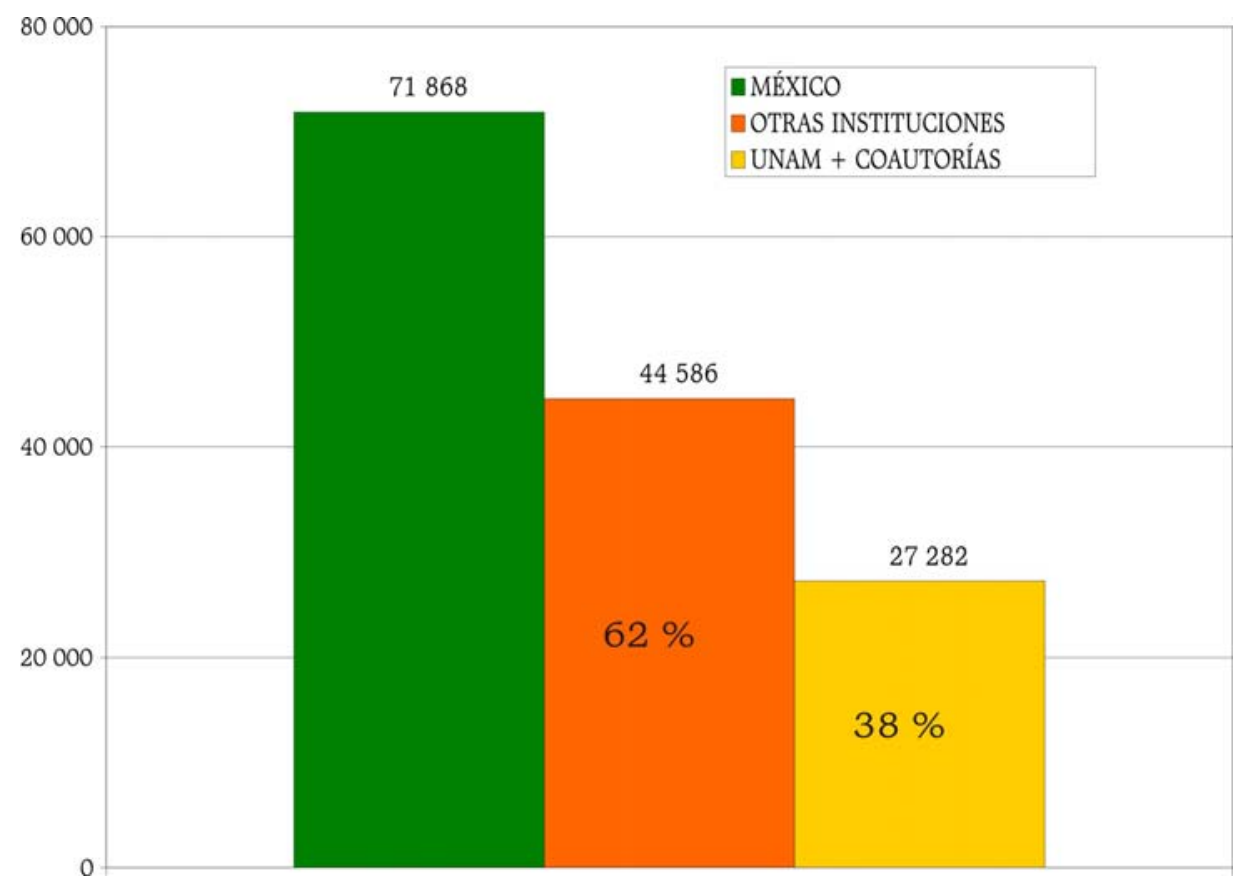

FUENTE: Laboratorio de Redes, Departamento de Modelación Matemática de Sistemas Sociales, IIMASUNAM, 2005.

Gráfica 2. Distribución de artículos (1981-2003).

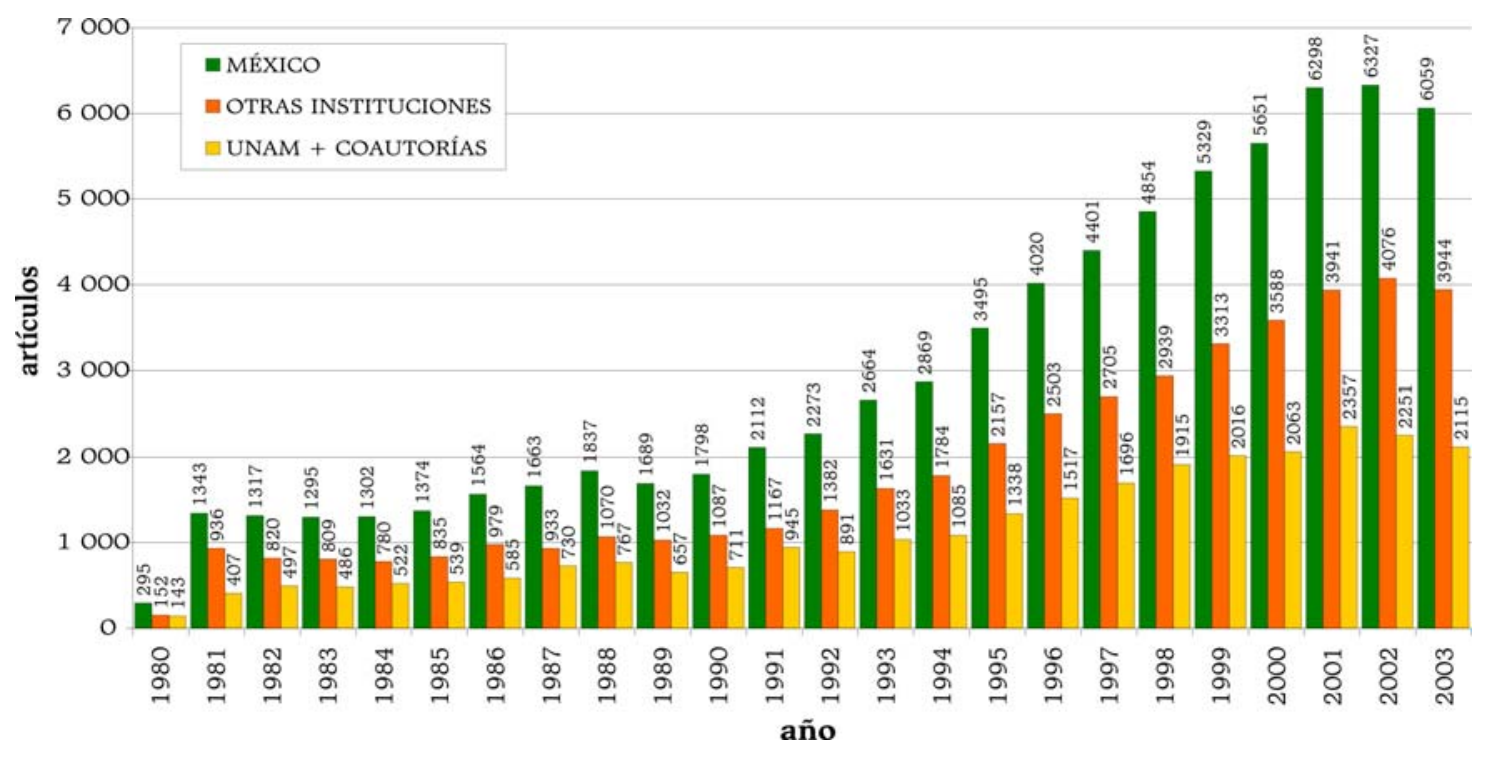

FUENTE: Laboratorio de Redes, Departamento de Modelación Matemática de Sistemas Sociales, IIMAS-UNAM, 2005.

Gráfica 3. Publicación anual de artículos. 
REDES- Revista hispana para el análisis de redes sociales

Vol.17,\#1, diciembre 2009

http: //revista-redes.rediris.es

\section{Autores por artículo}

El número de autores por artículo varía de 1 a 410. Los artículos escritos por 20 o menos autores son 71435, que representa más del $99 \%$ de los 71868 artículos (Gráfica 4).

Del año 1993 al 2003 la publicación de artículos en que participaron dos, tres y cuatro autores presenta un incremento anual mayor a los artículos publicados por un solo autor. Para el año de 2003 el número de artículos de un solo autor (498) equivale casi al $40 \%$ de los artículos escritos por tres autores (1229) y poco más del $14.7 \%$ de los artículos escritos por dos (1076), tres (1229) y cuatro autores (1073). De Solla Price ${ }^{9}$ en el análisis de la base de datos de chemical abstracts para el periodo 1910-1960 encontró que el número de autores múltiples se incremento en ese periodo; se aceleró la presentación por dos autores y posteriormente por tres autores creció con gran rapidez, el autor especuló que para 1980 ya no habría artículos con un solo autor, estamos muy cerca de esa afirmación. Smith ${ }^{10}$ encontró que el número de autores promedio aumentó de 1.3 a 1.7 entre 1946 y 1957 en el campo de la Psicología. En la Gráfica 4 tenemos la representación gráfica de los datos de la Tabla 2. El número de artículos escritos por 1, 2, 3, 4 y 5 autores representa el $83 \%$ de todos los artículos publicados entre 1980 y 2003 . El porcentaje de artículos publicados hasta por 5 autores, año por año, a partir de 1980 va de $96.3 \%$ al $83 \%$ en 2003 , desde luego que la diferencia al $100 \%$ es la suma de los artículos con seis hasta 410 autores.

\footnotetext{
${ }^{9}$ de Solla Price, D. J., "Little Science, Big Science”, Columbia University Press, New York, 1963.

${ }^{10}$ Smith, M., "The trend towar multiple authorship in Psicology", American Psicologist 13 (1958) 596 599.
} 
REDES- Revista hispana para el análisis de redes sociales

Vol.17, \#1, diciembre 2009

http: // revista-redes.rediris.es

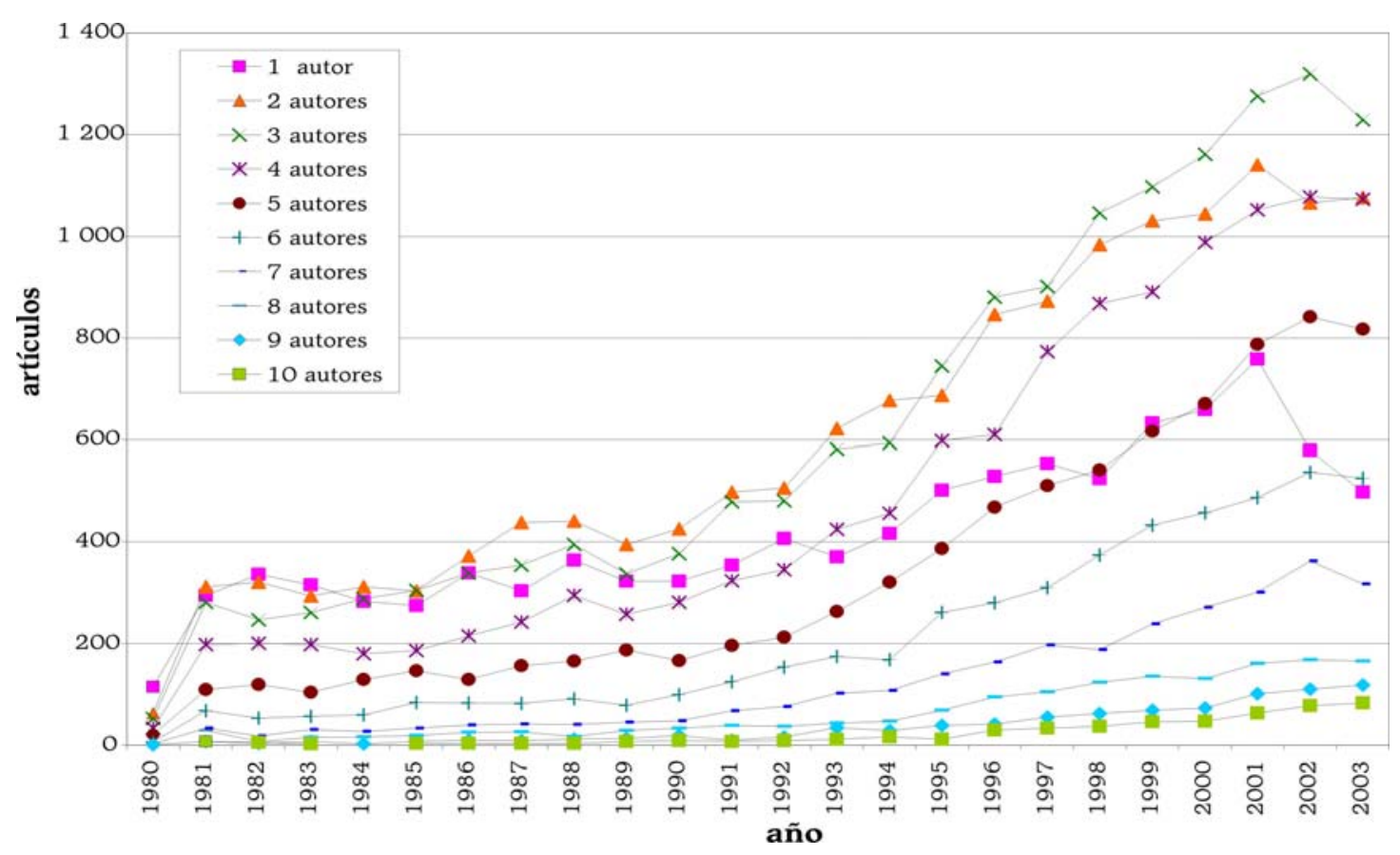

FUENTE: Laboratorio de Redes, Departamento de Modelación Matemática de Sistemas Sociales, IIMAS-UNAM, 2005.

Gráfica 4. Publicación anual de artículos por número de autores por artículo.

Los artículos con dos autores sobrepasan a los de un autor desde 1984, los de tres autores sobrepasan a los de un autor desde 1984. El caso de cuatro autores ocurre desde 1993. El caso de tres a dos autores ocurre en 1995, y el de cuatro a uno también ocurre en 1993. En 2003 el orden es 3, 2, 4, 5, 6, 1 autores por artículo. 
REDES- Revista hispana para el análisis de redes sociales

Vol.17, \#1, diciembre 2009

http: //revista-redes.rediris.es

\begin{tabular}{|c|c|c|c|c|c|c|c|c|c|c|c|c|c|c|c|c|c|c|c|c|}
\hline \multirow{2}{*}{ año } & \multicolumn{20}{|c|}{ autores } \\
\hline & 1 & 2 & 3 & 4 & 5 & 6 & 7 & 8 & 9 & 10 & $\mid 11$ & 12 & 13 & 14 & 15 & 16 & 17 & 18 & 19 & 20 \\
\hline 1980 & 115 & 63 & 52 & 33 & 21 & 6 & 3 & & 1 & & & & & & 1 & & & & & \\
\hline 1981 & 295 & 312 & 281 & 198 & 109 & 68 & 33 & 29 & 7 & 7 & & & & & 1 & & 2 & & & \\
\hline 1982 & 336 & 321 & 247 & 201 & 119 & 53 & 18 & 7 & 4 & 5 & 2 & 1 & 1 & & & & & 1 & & \\
\hline 1983 & 315 & 294 & 261 & 198 & 104 & 57 & 31 & 15 & 7 & 3 & & 1 & 1 & 2 & 1 & 1 & 2 & 1 & & 1 \\
\hline 1984 & 283 & 312 & 288 & 180 & 129 & 60 & 27 & 16 & 3 & & & 2 & 1 & & & & 1 & & & \\
\hline 1985 & 275 & 304 & 305 & 186 & 146 & 84 & 33 & 19 & 7 & 4 & 1 & 3 & & 1 & 2 & & 1 & 1 & & \\
\hline 1986 & 339 & 372 & 339 & 215 & 129 & 83 & 40 & 25 & 10 & 4 & 2 & 1 & 2 & & 1 & & 1 & & & \\
\hline 1987 & 304 & 438 & 354 & 242 & 156 & 82 & 42 & 26 & 9 & 4 & 2 & & & & & & & & 2 & \\
\hline 1988 & 364 & 441 & 395 & 295 & 165 & 91 & 41 & 17 & 12 & 4 & 4 & 5 & & 1 & 2 & & & & & \\
\hline 1989 & 323 & 395 & 337 & 258 & 187 & 79 & 45 & 29 & 14 & 7 & 4 & 6 & & & 1 & & 1 & & & \\
\hline 1990 & 323 & 426 & 377 & 281 & 166 & 99 & 48 & 33 & 19 & 9 & 5 & 3 & & 2 & & & 1 & 1 & 2 & \\
\hline 1991 & 354 & 498 & 479 & 324 & 196 & 125 & 68 & 39 & 10 & 7 & 4 & 2 & 2 & 1 & 1 & 1 & & & & \\
\hline 1992 & 407 & 506 & 481 & 345 & 212 & 154 & 76 & 37 & 16 & 9 & 5 & 4 & 4 & 1 & & 1 & 2 & 2 & & \\
\hline 1993 & 371 & 622 & 582 & 425 & 263 & 174 & 102 & 43 & 34 & 12 & 7 & 5 & 5 & 4 & 1 & 2 & 3 & 1 & & \\
\hline 1994 & 417 & 677 & 594 & 456 & 321 & 168 & 108 & 47 & 29 & 16 & 8 & 5 & 2 & 1 & 3 & 2 & 2 & 1 & 1 & 1 \\
\hline 1995 & 502 & 687 & 745 & 598 & 387 & 261 & 140 & 69 & 39 & 12 & 11 & 6 & 7 & 2 & 1 & 1 & 2 & & 2 & ? \\
\hline 1996 & 529 & 846 & 880 & 610 & 468 & 280 & 164 & 95 & 42 & 30 & 12 & 11 & 9 & 3 & & 5 & 1 & & 4 & $t$ \\
\hline 1997 & 554 & 872 & 901 & 773 & 511 & 310 & 197 & 105 & 55 & 33 & 20 & 15 & 10 & 7 & & 3 & 7 & 3 & 2 & 1 \\
\hline 1998 & 524 & 983 & 1046 & 868 & 541 & 374 & 188 & 124 & 62 & 37 & 22 & 8 & 7 & 10 & 6 & 2 & 7 & 4 & 3 & 2 \\
\hline 1999 & 633 & 1030 & 1097 & 890 & 616 & 433 & 239 & 136 & 69 & 46 & 31 & 15 & 17 & 9 & 5 & 5 & 9 & 5 & 1 & 3 \\
\hline 2000 & 659 & 1044 & 1161 & 988 & 671 & 457 & 271 & 131 & 73 & 47 & 18 & 21 & 8 & 16 & 7 & 11 & 9 & 5 & 6 & 2 \\
\hline 2001 & 758 & 1141 & 1276 & 1052 & 787 & 487 & 301 & 161 & 101 & 63 & 30 & 19 & 17 & 12 & 8 & 7 & 7 & 2 & 4 & 3 \\
\hline 2002 & 579 & 1066 & 1320 & 1077 & 841 & 537 & 362 & 168 & 110 & 78 & 43 & 12 & 18 & 14 & 16 & 10 & 8 & 1 & 5 & 5 \\
\hline 2003 & 498 & 1076 & 1229 & 1073 & 817 & 525 & 317 & 165 & 118 & 83 & 30 & 26 & 15 & 15 & 10 & 8 & 5 & 2 & 6 & 7 \\
\hline \multirow{3}{*}{ 草 y } & 0057 & 14726 & 15027 & 11766 & 8062 & 5047 & 2894 & 1536 & 851 & 520 & 261 & 171 & 126 & 101 & 67 & 59 & 71 & 30 & 38 & 25 \\
\hline & \multicolumn{10}{|c|}{70486} & & & & & & & & & & \\
\hline & \multicolumn{20}{|c|}{71435} \\
\hline
\end{tabular}

FUENTE: Laboratorio de Redes, Departamento de Modelación Matemática de Sistemas Sociales, IIMAS-UNAM, 2005.

Tabla 2. Publicación anual de artículos por 1,2,3...,20 autores por artículo.

\section{Artículos por Entidad Federativa}

Los investigadores afiliados a Instituciones Nacionales que se localizan en Distrito Federal son autores de 48056 de un total de 71868 artículos, lo que representa cerca del $67 \%$ del total (Gráfica 5). Para el conteo de la publicación de artículos para cada entidad Federativa se consideraron tanto los artículos escritos por autores afiliados a instituciones de dicha entidad, como los escritos en coautoría con autores afiliados a instituciones de las otras entidades federativas.

Los investigadores afiliados a Instituciones Nacionales que se localizan en Distrito Federal y en los estados de Morelos, Puebla, Guanajuato y Estado de México, son autores o coautores de $57161^{11}$ de un total de 71868 artículos, lo que representa cerca del $80 \%$. Los investigadores afiliados a Instituciones Nacionales que se localizan en Distrito Federal y en los estados de Morelos, Puebla, Baja California, Guanajuato, Jalisco y Nuevo León, son autores o coautores de 62164 de un total de 71868 artículos, lo que representa más del $86 \%$. Estas entidades tienen una total superior a 2000 artículos.

\footnotetext{
${ }^{11}$ Estas cifras corresponde al total acumulado de dichos Estados.
} 
REDES- Revista hispana para el análisis de redes sociales Vol.17,\#1, diciembre 2009

http: // revista-redes.rediris.es

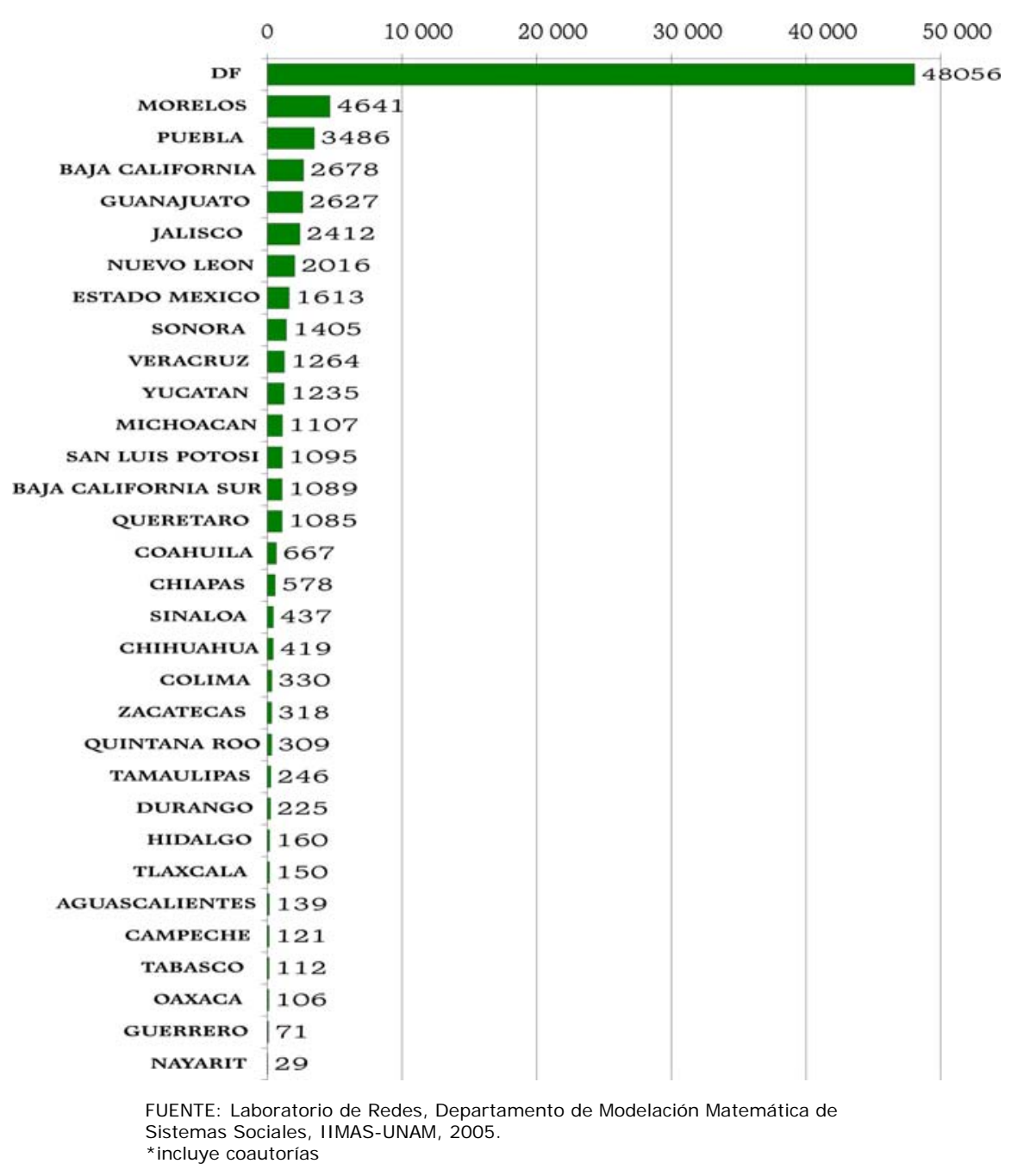

Gráfica 5. Artículos* por Entidad Federativa.

\section{Colaboración con diversos países}

Los investigadores afiliados a Instituciones Nacionales son coautores en 25198 artículos con investigadores de instituciones de 150 países, de un total de 71868 artículos, lo que representa más del $35 \%$ del total nacional registrado por ISIThomson en el periodo bajo estudio. En las Figuras 1 y 2 se muestra la localización geográficas de instituciones con que México colabora a nivel internacional. 
REDES- Revista hispana para el análisis de redes sociales Vol.17,\#1, diciembre 2009

http: //revista-redes.rediris.es

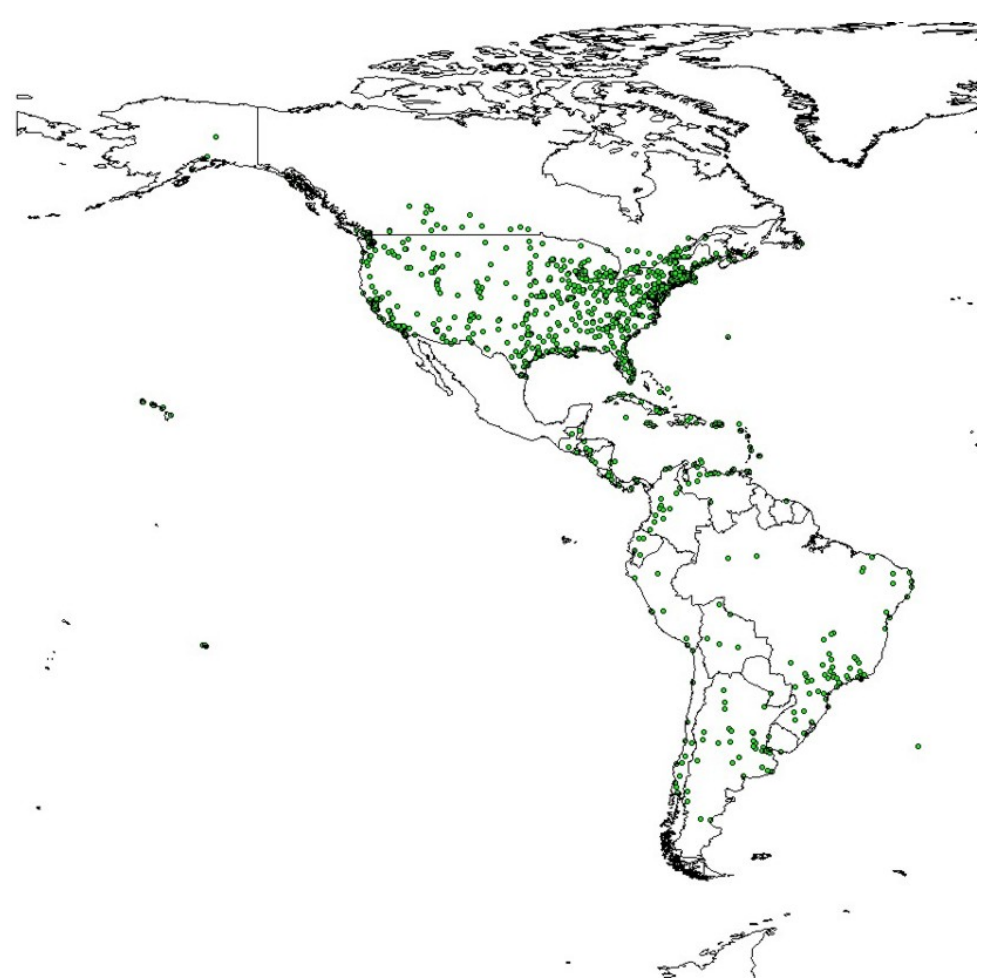

Figura 1. Colaboración con instituciones del extranjero.

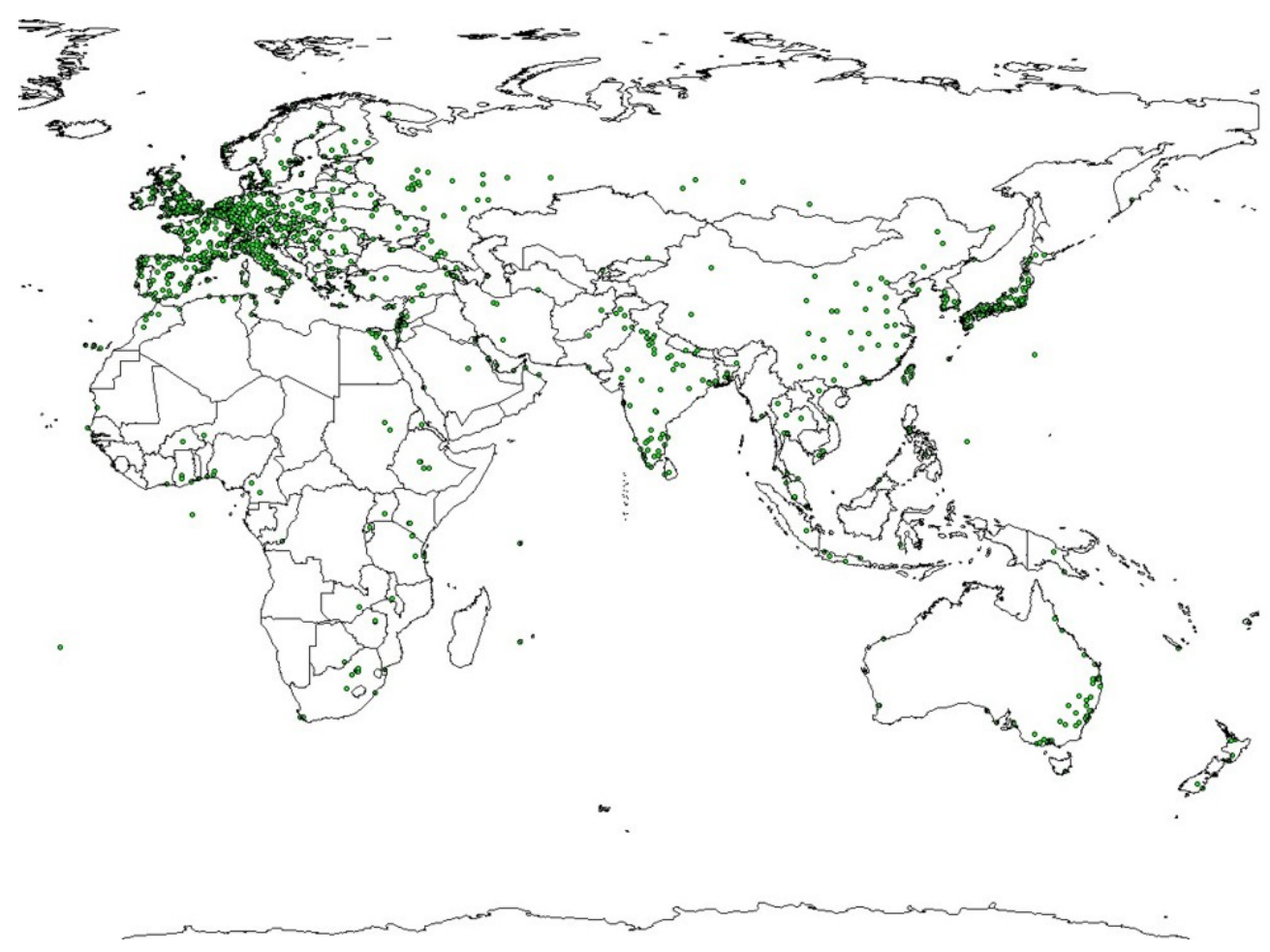

Figura 2. Colaboración con instituciones del extranjero. 
REDES- Revista hispana para el análisis de redes sociales

Vol.17,\#1, diciembre 2009

http: //revista-redes.rediris.es

\section{UNAM}

\section{Publicación total de artículos}

Los artículos contenidos en esta base de datos fueron escritos por autores afiliados a institutos y centros de investigación; escuelas y facultades, y otras entidades de la UNAM. Hay 2023 artículos que no especifican la entidad de afiliación, por lo que el total de artículos identificados fue de 25259.

Los Institutos y Centro de investigación de la UNAM se agrupan en dos subsistemas: el de la Investigación Científica (SIC) y el de la Investigación en Humanidades $(\mathrm{SIH})$; las Escuelas y Facultades son consideradas otro subsistema (SEF); y las otras entidades se agruparon junto con la Secretaría General (SG) de la UNAM ya que esta secretaría las coordina administrativamente.

El Subsistema de la Investigación Científica (SIC) contribuye con el $75.6 \%$ de la publicación de artículos científicos de la UNAM, el Subsistema de Escuelas y Facultades (SEF) con el $28.8 \%$, y el resto por el Subsistema de Humanidades (SIH) y la Secretaría General (SG).

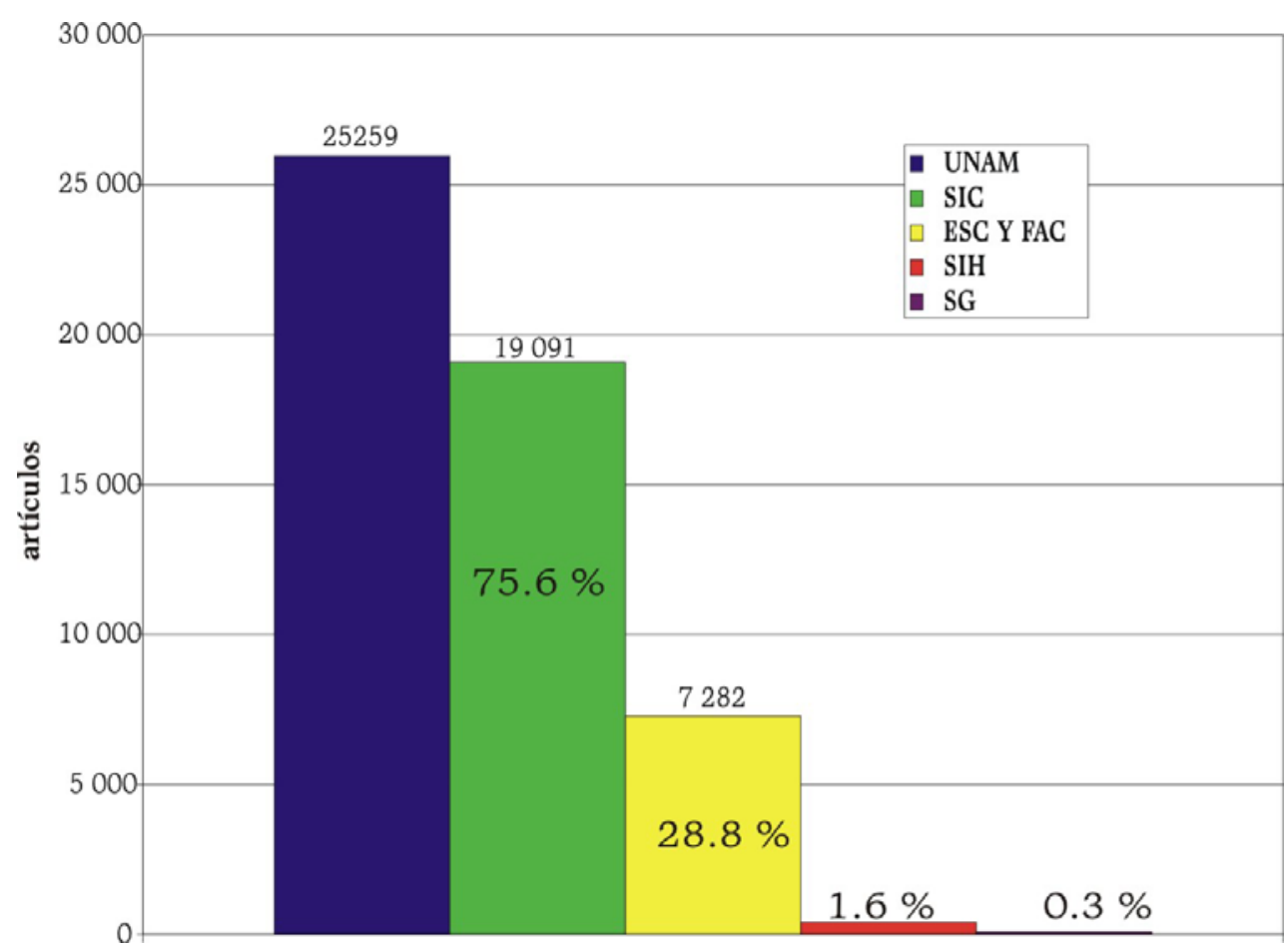

FUENTE: Laboratorio de Redes, Departamento de Modelación Matemática de Sistemas Sociales, IIMAS-UNAM, 2005.

Gráfica 6. Producción total de artículos UNAM. 
REDES- Revista hispana para el análisis de redes sociales

Vol.17,\#1, diciembre 2009

http: //revista-redes.rediris.es

\section{Publicación anual de artículos}

Del año de 1990 al 2001 el crecimiento anual promedio del SIC es del $12.3 \%$ y el del SEF es de 10.8\%, (Gráfica 7).

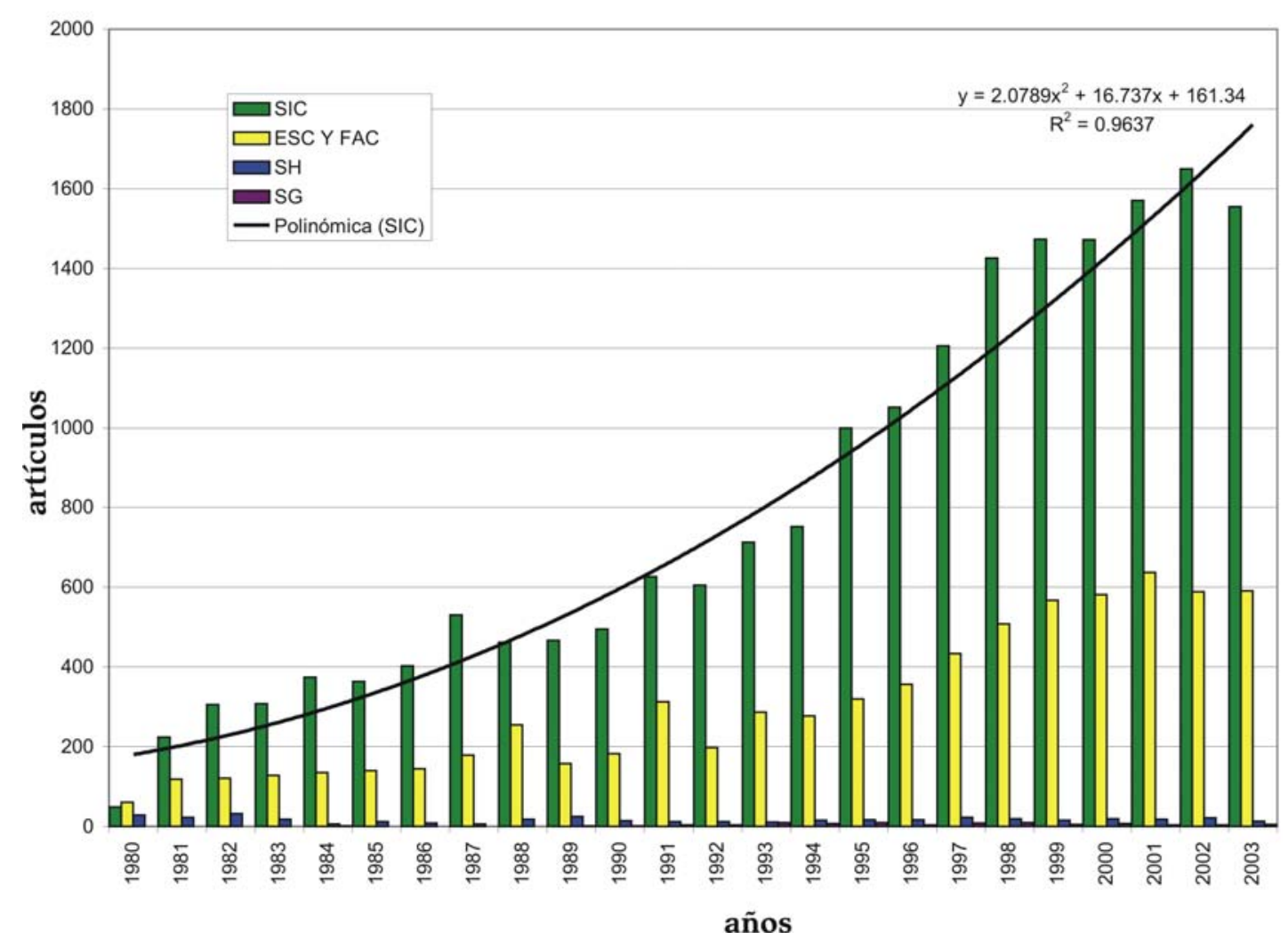

FUENTE: Laboratorio de Redes, Departamento de Modelación Matemática de Sistemas Sociales, IIMAS-UNAM, 2005.

Gráfica 7. Producción anual por subsistema UNAM.

\section{Colaboración entre subsistemas}

Las entidades de la UNAM publicaron 2981 artículos en colaboración con otras entidades de la propia UNAM, esto representa el $11.8 \%$ del total de publicaciones.

En la Figura 3 se muestra la estructura de colaboración entre los diferentes subsistemas en base al número de artículos conjuntos entre entidades de la UNAM. El total de artículos por entidad se representa por diámetro del círculo asociado a cada entidad, y el número de colaboraciones entre entidades por el ancho de las líneas que unen los círculos asociados a cada entidad. 
REDES- Revista hispana para el análisis de redes sociales

Vol.17,\#1, diciembre 2009

http: //revista-redes.rediris.es

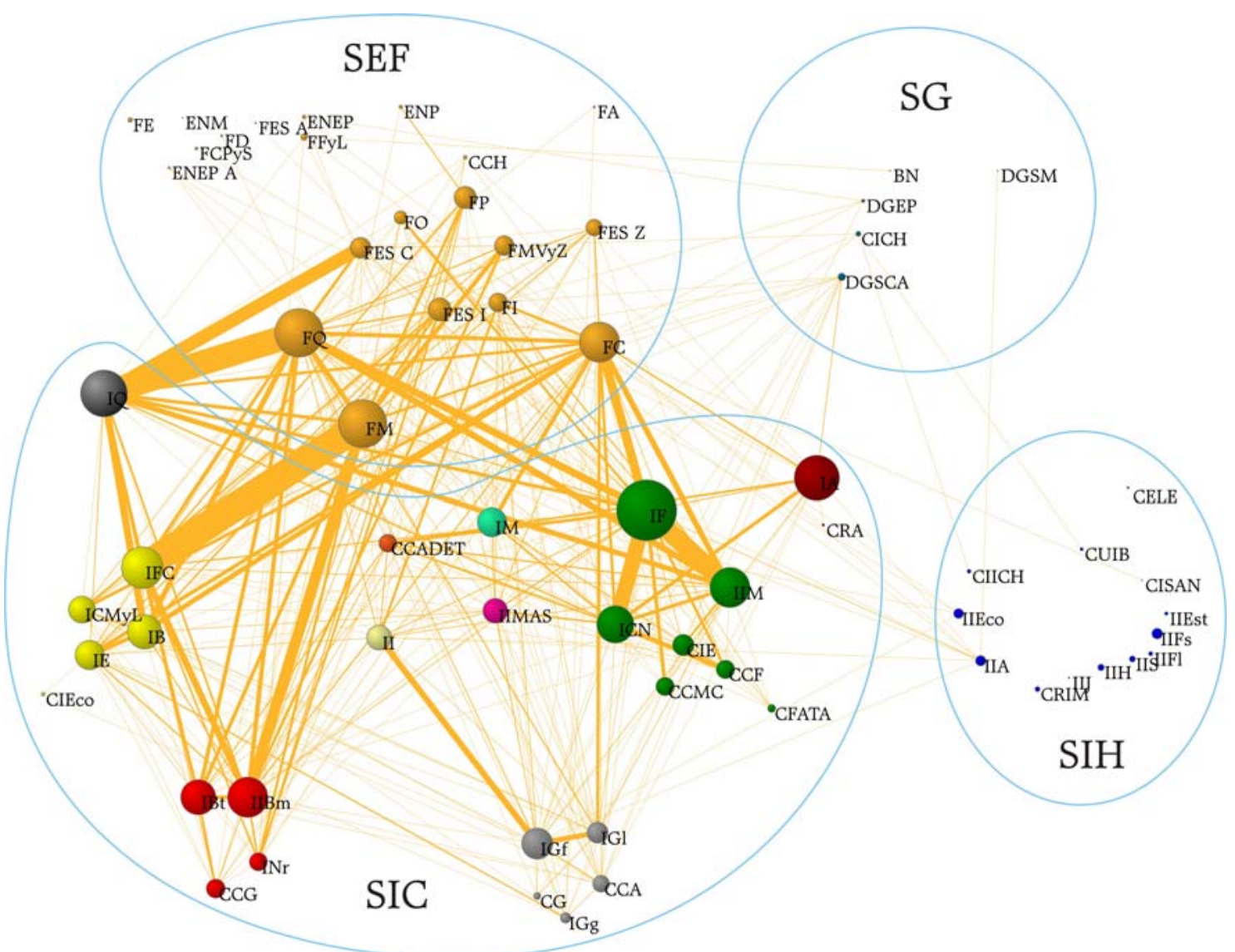

FUENTE: Laboratorio de Redes, Departamento de Modelación Matemática de Sistemas Sociales, IIMAS-UNAM, 2005.

Figura 3. Colaboración entre subsistemas UNAM. 
REDES- Revista hispana para el análisis de redes sociales

Vol.17,\#1, diciembre 2009

http: //revista-redes.rediris.es

\section{Subsistema de la Investigación Científica ${ }^{12}$}

En el año de 1945 se creó la Coordinación de la Investigación Científica y se integraron el Instituto de Biología que fue creado en 1929, el de Química en 1941, el de Física en 1938, el de Matemáticas en 1942, el de Geología en 1929, el de Geofísica en 1945, el de Geografía que data de 1933 y el Observatorio Astronómico que se transformó en el Instituto de Astronomía en 1967.

La Coordinación de la Investigación Científica se crea con el objetivo de orientar los trabajos de los institutos y centros, estudiar y proponer cambios en su organización y trabajo y propiciar su desarrollo, de acuerdo a lo establecido en el estatuto general de la Universidad. Hacia 1980 los institutos y centro en operación eran, además de los mencionados, el Centro de Investigaciones en Fisiología Celular, el Centro de Ciencias del Mar y Limnología, el Instituto de Investigaciones Biomédicas, el Centro de Investigaciones sobre Fijación del Nitrógeno, el Centro de Estudios Nucleares, el Instituto de Investigaciones en Materiales, el Instituto de Investigaciones en Matemáticas Aplicadas y en Sistemas, el Centro de Instrumentos, el Centro de Ciencias de la Atmósfera y el Instituto de Ingeniería. Para 2003 las entidades del SIC (Tabla 3) están agrupadas en tres áreas de conocimiento: Ciencias Físico Matemáticas (CFM), Ciencias Químico-Biológicas y de la Salud (CQByS) y Ciencias de la Tierra e Ingenierías (CTI).

Las entidades de la UNAM publicaron 1583 artículos en colaboración con otras entidades del otro subsistema, que representa el 6.3\% de los 25259 artículos UNAM.

\section{Publicaciones}

La entidad que participó en el mayor número de artículos fue el Instituto de Física con un total de 3040. En la Gráfica 8 se muestra el total de artículos por entidad. Las entidades están agrupadas por área de conocimiento: Ciencias Físico Matemáticas (amarillo), Ciencias Químico-Biológicas y de la Salud (azul) y Ciencias de la Tierra e Ingenierías (verde).

\footnotetext{
12 Nos referiremos indistintamente como: Subsistema de la Investigación Científica, Subsistema o SIC.
} 
REDES- Revista hispana para el análisis de redes sociales

Vol.17, \#1, diciembre 2009

http://revista-redes.rediris.es

\begin{tabular}{|c|c|c|c|}
\hline & & & $\begin{array}{c}\text { Fecha } \\
\text { de } \\
\text { creación }\end{array}$ \\
\hline CFM & Instituto de Astronomía & IA & 1929 \\
\hline CFM & Instituto de Ciencias Nucleares & ICN & 1972 \\
\hline CFM & Instituto de Física & IF & 1938 \\
\hline CFM & Instituto de Investigaciones en Matemáticas Aplicadas y en Sistemas & IIMAS & 1958 \\
\hline CFM & Instituto de Investigaciones en Materiales & IIM & 1967 \\
\hline CFM & Instituto de Matemáticas & IM & 1942 \\
\hline CFM & Centro de Ciencias Aplicadas y Desarrollo Tecnológico & CCADET & 1971 \\
\hline CFM & Centro de Ciencias de la Materia Condensada & CCMC & 1997 \\
\hline CFM & Centro de Ciencias Físicas & CCF & 1998 \\
\hline CFM & Centro de Física Aplicada y Tecnología Avanzada & CFATA & 2002 \\
\hline CFM & Centro de Investigaciones en Energía & $\mathrm{CIE}$ & 1996 \\
\hline CFM & Centro de Radioastronomía y Astrofísica & CRA & 2003 \\
\hline CQByS & Instituto de Biología & $\mathrm{IB}$ & 1929 \\
\hline CQByS & Instituto de Biotecnología & IBt & 1982 \\
\hline CQByS & Instituto de Ciencias del Mar y Limnología & ICMyL & 1973 \\
\hline CQByS & Instituto de Ecología & IE & 1984 \\
\hline CQByS & Instituto de Fisiología Celular & IFC & 1979 \\
\hline CQByS & Instituto de Investigaciones Biomédicas & $\mathrm{IIBm}$ & 1941 \\
\hline CQByS & Instituto de Neurobiología & $\mathrm{INr}$ & 1993 \\
\hline CQBYS & Instituto de Química & IQ & 1941 \\
\hline CQByS & Centro de Ciencias Genómicas & CCG & 1980 \\
\hline CQByS & Centro de Investigaciones en Ecosistemas & $\mathrm{ClECO}$ & 2003 \\
\hline CTI & Instituto de Geofísica & IGf & 1945 \\
\hline CTI & Instituto de Geología & IGI & 1929 \\
\hline CTI & Instituto de Ingeniería & II & 1976 \\
\hline CTI & Instututo de Geografía & $\mathrm{IGg}$ & 1943 \\
\hline CTI & Centro de Ciencias de la Atmósfera & CCA & 1977 \\
\hline $\mathrm{CTI}$ & Centro de Geociencias & CG & 2002 \\
\hline
\end{tabular}

FUENTE: Laboratorio de Redes, Departamento de Modelación Matemática de Sistemas Sociales, IIMAS-UNAM, 2005.

Tabla 3. Entidades del Subsistema de la Investigación Científica SIC-UNAM.

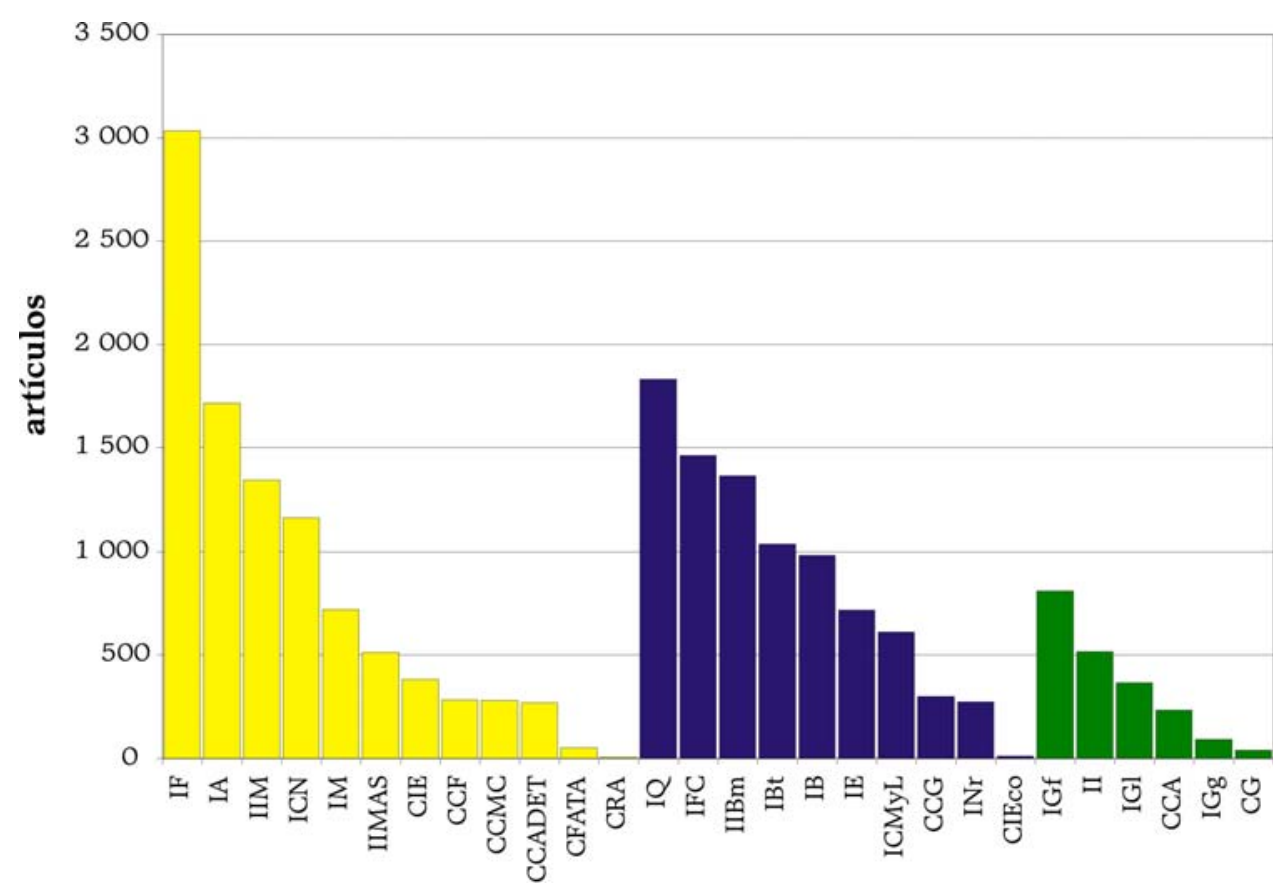

FUENTE: Laboratorio de Redes, Departamento de Modelación Matemática de Sistemas Sociales, IIMAS-UNAM, 2005.

Gráfica 8. Publicación total de artículos* SIC-UNAM.

* incluye coautorías 
REDES- Revista hispana para el análisis de redes sociales

Vol.17,\#1, diciembre 2009

http: //revista-redes.rediris.es

\section{Publicación anual de artículos}

Si bien se observa un incremento sustancial a partir del año de 1990, es manifiesto el cambio drástico en el crecimiento de artículos en el año 2000 en las entidades de las áreas CFM y CQByS, crecimiento que no ha alcanzado el ritmo de los años 1990; cambio que no es tan manifiesto en las entidades del área CTI (Gráficas 9, 10 y 11: Tabla 4).

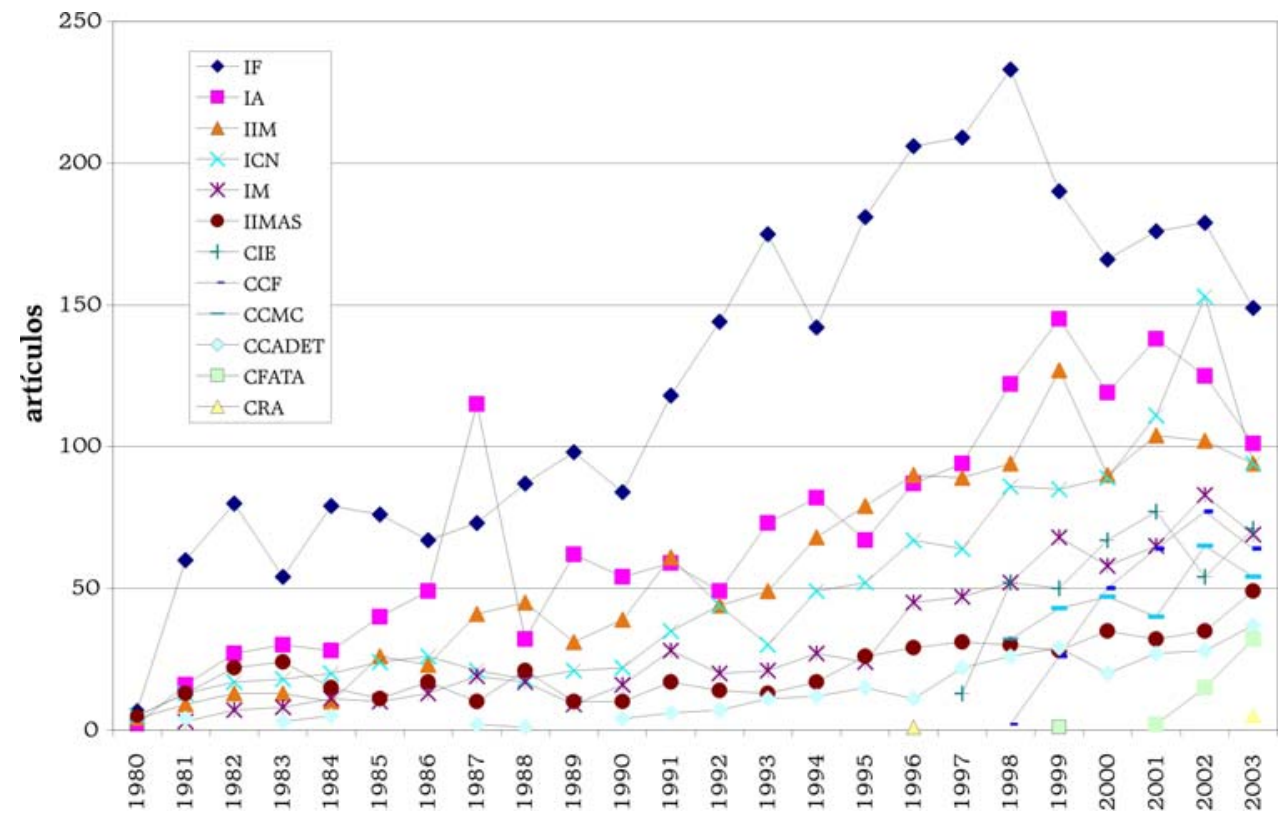

FUENTE: Laboratorio de Redes, Departamento de Modelación Matemática de Sistemas Sociales, IIMAS-UNAM, 2005.

Gráfica 9. Publicación anual de artículos* SIC-UNAM. Área Ciencias Físico Matemáticas. * incluye coautorías

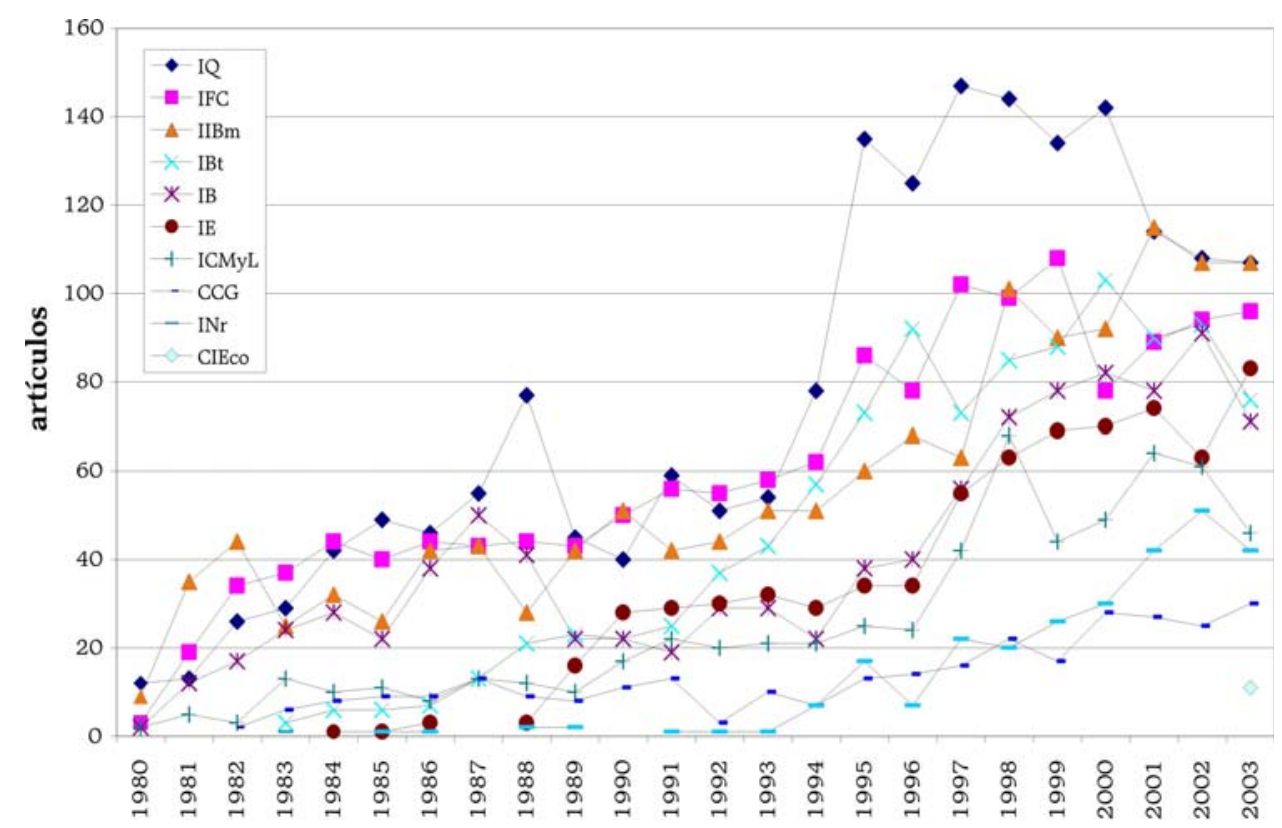

FUENTE: Laboratorio de Redes, Departamento de Modelación Matemática de Sistemas Sociales, IIMAS-UNAM, 2005.

Gráfica 10. Publicación anual de artículos* SIC-UNAM. Área Ciencias Químico-Biológicas y de la Salud * incluye coautorías 
REDES- Revista hispana para el análisis de redes sociales

Vol.17,\#1, diciembre 2009

http: //revista-redes.rediris.es

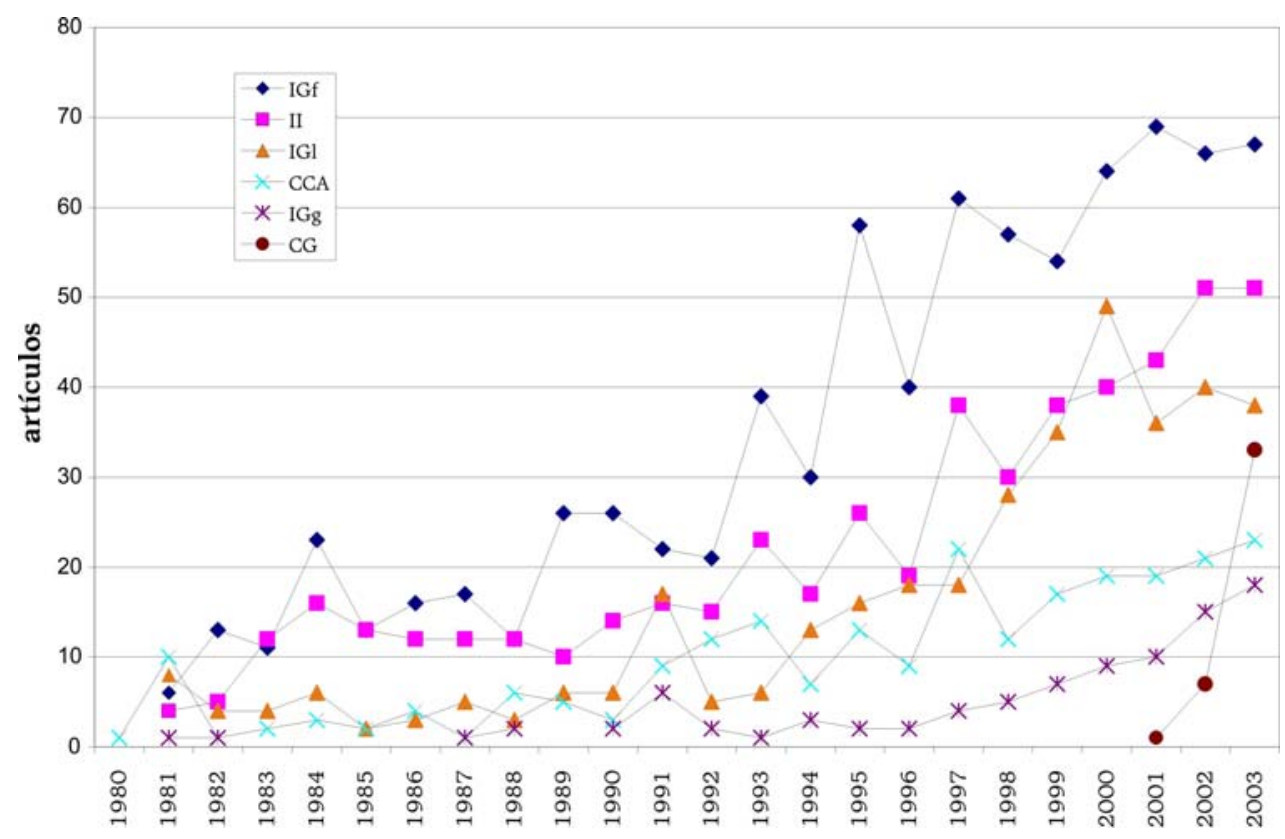

FUENTE: Laboratorio de Redes, Departamento de Modelación Matemática de Sistemas Sociales, IIMAS-UNAM, 2005.

Gráfica 11. Publicación anual de artículos* SIC-UNAM. Área Ciencias de la Tierra e Ingenierías *incluye coautorías

\begin{tabular}{|c|c|c|c|c|c|c|c|c|c|c|c|c|c|c|c|c|c|c|c|c|c|c|c|c|c|}
\hline Entidad & Total & $\begin{array}{l}\circ \\
\infty \\
\stackrel{-}{-1} \\
\end{array}$ & $\begin{array}{l}-1 \\
\infty \\
0 \\
-1\end{array}$ & $\begin{array}{l}N \\
\infty \\
\text { O } \\
\end{array}$ & $\begin{array}{l}m \\
\infty \\
0 \\
\end{array}$ & \begin{tabular}{l}
\multirow{1}{}{} \\
0 \\
$\sigma$ \\
\end{tabular} & $\begin{array}{l}0 \\
\infty \\
0 \\
\\
\end{array}$ & \begin{tabular}{|l|l}
0 \\
0 \\
0 \\
-1 \\
\end{tabular} & 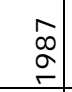 & $\begin{array}{l}\infty \\
\infty \\
o \\
\sim \\
\end{array}$ & 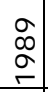 & \begin{tabular}{|l|} 
\\
\\
О \\
\end{tabular} & $\begin{array}{l}\text { ने } \\
\text { बे }\end{array}$ & $\begin{array}{l}\text { Лิ } \\
\text { ने } \\
\end{array}$ & $\begin{array}{l}\text { ò } \\
\text { } \\
-\end{array}$ & \begin{tabular}{l}
\multirow{\sigma}{}{} \\
बे \\
\end{tabular} & 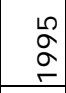 & $\begin{array}{l}0 \\
\text { Оे } \\
\end{array}$ & $\begin{array}{l}\hat{\sigma} \\
\text { बे } \\
\end{array}$ & $\begin{array}{l}\infty \\
\stackrel{2}{ } \\
\text { ने } \\
\end{array}$ & $\begin{array}{l}\text { बे } \\
\text { Оે } \\
\end{array}$ & $\begin{array}{l}\text { ○े } \\
\text { ¿ } \\
\end{array}$ & $\begin{array}{l}\text { ¿े } \\
\text { ○ } \\
\text {. }\end{array}$ & $\begin{array}{l}\mathrm{N} \\
\text { ¿े } \\
\text { N }\end{array}$ & N \\
\hline IF & 3034 & 7 & 60 & 80 & 54 & 79 & 76 & 67 & 73 & 87 & 98 & 84 & 118 & 144 & 175 & 142 & 181 & 206 & 209 & 233 & 190 & 166 & 176 & 179 & 149 \\
\hline IA & 1716 & 2 & 16 & 27 & 30 & 28 & 40 & 49 & 115 & 32 & 62 & 54 & 59 & 49 & 73 & 82 & 67 & 87 & 94 & 122 & 145 & 119 & 138 & 125 & 101 \\
\hline IIM & 1347 & 4 & 9 & 13 & 13 & 10 & 26 & 23 & 41 & 45 & 31 & 39 & 61 & 44 & 49 & 68 & 79 & 90 & 89 & 94 & 127 & 90 & 104 & 102 & 94 \\
\hline $\mathrm{ICN}$ & 1164 & 5 & 13 & 17 & 18 & 20 & 24 & 26 & 21 & 18 & 21 & 22 & 35 & 44 & 30 & 49 & 52 & 67 & 64 & 86 & 85 & 89 & 111 & 153 & . \\
\hline IM & 720 & & 3 & 7 & 8 & 11 & 10 & 13 & 19 & 17 & 9 & 16 & 28 & 20 & 21 & 27 & 24 & 45 & 47 & 52 & 68 & 58 & 65 & 83 & 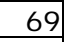 \\
\hline $11 \mathrm{MA}$ & 514 & 5 & 13 & 22 & 24 & 15 & 11 & 17 & 10 & 21 & 10 & 10 & 17 & 14 & 13 & 17 & 26 & 29 & 31 & 30 & 28 & 35 & 32 & 35 & 49 \\
\hline $\mathrm{ClE}$ & 384 & & & & & & & & & & & & & & & & & & 13 & 52 & 50 & 67 & 77 & 54 & 71 \\
\hline $\mathrm{CCF}$ & 284 & & & & & & & & & & & & & & & & & & & 2 & 26 & 50 & 64 & 77 & 64 \\
\hline CCMC & 281 & & & & & & & & & & & & & & & & & & & 32 & 43 & 47 & 40 & 65 & 5 \\
\hline $\mathrm{CCA}$ & 270 & & 4 & & 3 & 5 & & & 2 & 1 & & 4 & 6 & 7 & 11 & 12 & 15 & 11 & 22 & 26 & 29 & 20 & 27 & 28 & 3 \\
\hline CFAT & 52 & & & & & & & & & & & & & & & & & & & & 1 & & 2 & 15 & 3 \\
\hline CRA & 6 & & & & & & & & & & & & & & & & & 1 & & & & & & & \\
\hline IQ & 32 & 12 & 13 & 26 & 29 & 42 & 49 & 46 & 55 & 77 & 45 & 40 & 59 & 51 & 54 & 78 & 135 & 125 & 147 & 144 & 134 & 142 & 114 & 108 & 107 \\
\hline IFC & 163 & 3 & 19 & 34 & 37 & 44 & 40 & 44 & 43 & 44 & 43 & 50 & 56 & 55 & 58 & 62 & 86 & 78 & 102 & 99 & 108 & 78 & 89 & 94 & 9 \\
\hline $\mathrm{IIBm}$ & 1369 & 9 & 35 & 44 & 25 & 32 & 26 & 42 & 43 & 28 & 42 & 51 & 42 & 44 & 51 & 51 & 60 & 68 & 63 & \begin{tabular}{|l|}
101 \\
\end{tabular} & 90 & 92 & \begin{tabular}{|l|}
115 \\
\end{tabular} & 107 & 107 \\
\hline $\mathrm{IBt}$ & 1037 & & & & 3 & 6 & 6 & 7 & 13 & 21 & 23 & 22 & 25 & 37 & 43 & 57 & 73 & 92 & 73 & 85 & 88 & 103 & 90 & 93 & 76 \\
\hline IB & 983 & 2 & 12 & 17 & 24 & 28 & 22 & 38 & 50 & 41 & 22 & 22 & 19 & 29 & 29 & 22 & 38 & 40 & 56 & 72 & 78 & 82 & 78 & 91 & 71 \\
\hline IE & 719 & & & & & 1 & 1 & 3 & & 3 & 16 & 28 & 29 & 30 & 32 & 29 & 34 & 34 & 55 & 63 & 69 & 70 & 74 & 63 & 8 \\
\hline ICMy & 611 & 2 & 5 & 3 & 13 & 10 & 11 & 8 & 13 & 12 & 10 & 17 . & 22 & 20 & 21 & 21 & 25 & 24 & 42 & 68 & 44 & 49 & 64 & 61 & 46 \\
\hline CCG & 300 & & & 2 & 6 & 8 & 9 & 9 & 13 & 9 & 8 & 11 & 13 & 7 & 10 & 7 & 13 & 14 & 16 & 22 & 17 & 28 & 27 & 25 & 3 \\
\hline $\mathrm{INr}$ & 274 & & & & 1 & & 1 & 1 & & 2 & 2 & & 1 & $\perp$ & 1 & 1 & 17 & 7 & 22 & 20 & 26 & 30 & 42 & 51 & 42 \\
\hline $\mathrm{CIEC}$ & \pm & & & & & & & & & & & & & & & & & & & & & & & & 1 \\
\hline IGf & 811 & & 6 & 13 & 11 & 23 & 13 & 16 & 17 & 12 & 26 & 26 & 22 & 21 & 39 & 30 & 58 & 40 & 61 & 57 & 54 & 64 & 69 & 66 & 6 \\
\hline II & 17 & & 4 & 5 & 12 & 16 & 13 & 12 & 12 & 12 & 10 & 14 & 16 & 15 & 23 & 17 & 26 & 19 & 38 & 30 & 38 & 40 & 43 & 51 & 5 \\
\hline $\mid \mathrm{Gl}$ & 367 & & 8 & 4 & 4 & 6 & 2 & 3 & 5 & 3 & 6 & 6 & 17 & 5 & 6 & 13 & 16 & 18 & 18 & 28 & 35 & 49 & 36 & 40 & 3 \\
\hline CCA & 235 & 1 & 10 & 1 & 2 & 3 & 2 & 4 & 1 & 6 & 5 & 3 & 9 & 12 & 14 & 7 & 13 & 9 & 22 & 12 & 17 & 19 & 19 & 21 & 23 \\
\hline $\mathrm{IGg}$ & 91 & & 1 & 1 & & & & & 1 & 2 & & 2 & 6 & 2 & 1 & 3 & 2 & 2 & 4 & 5 & 7 & 9 & 10 & 15 & 18 \\
\hline CG & 41 & & & & & & & & & & & & & & & & & & & & & & 1 & 7 & 3 \\
\hline
\end{tabular}

FUENTE: Laboratorio de Redes, Departamento de Modelación Matemática de Sistemas Sociales, IIMAS-UNAM, 2005.

Tabla 4. Publicación total de artículos* SIC-UNAM.

* incluye coautorías 
REDES- Revista hispana para el análisis de redes sociales

Vol.17,\#1, diciembre 2009

http: //revista-redes.rediris.es

\section{Colaboración con instituciones del extranjero}

Los investigadores afiliados a entidades del SIC de la UNAM han colaborado con investigadores afiliados a 2405 Instituciones de 103 países.

En la Gráfica 12 se muestran los primeros 30 países con que se ha colaborado en más de 50 artículos.

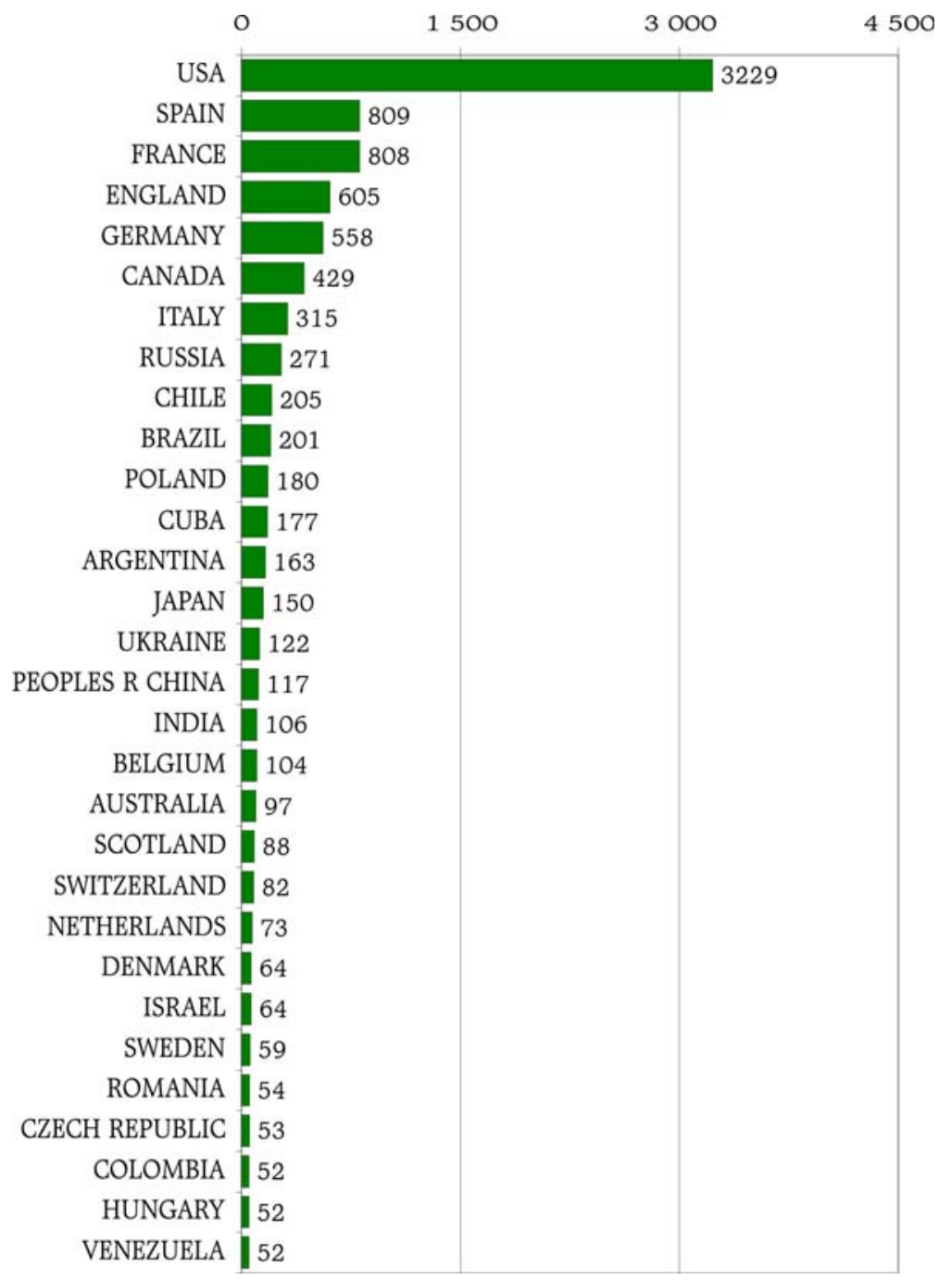

FUENTE: Laboratorio de Redes, Departamento de Modelación Matemática de Sistemas Sociales, IIMAS-UNAM, 2005.

Gráfica 12. Colaboración SIC-UNAM con diversos países.

En las Tablas 5, 6 y 7 se muestra la colaboración con diversas instituciones extranjeras en más de 50 artículos, por cada una de las entidades del SIC. La Institución ${ }^{13}$ con la que han colaborado más las entidades del Subsistema el consejo Superior de Investigaciones Científicas de España, con un total de 281 artículos.

\footnotetext{
${ }^{13}$ Los nombres de las instituciones que se manejan en las tablas siguientes, corresponde a la forma en que ISI-THOMSON las identifica en sus diversas bases de datos.
} 
REDES- Revista hispana para el análisis de redes sociales

Vol.17, \#1, diciembre 2009

http: //revista-redes.rediris.es

\begin{tabular}{|c|c|c|c|c|c|c|c|c|c|c|c|c|c|}
\hline país & Institución & $\underline{=}$ & $\leq$ & $\underline{\Sigma}$ & $\underline{\underline{u}}$ & $\Sigma$ & $\sum_{\equiv}^{U}$ & $\bar{u}$ & U & $\sum_{U}^{U}$ & $\begin{array}{l} \\
\text { 岁 } \\
\text { 它 }\end{array}$ & 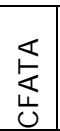 & $\underset{\mathbb{S}}{\mathbb{U}}$ \\
\hline SPAIN & CONSEJ O SUPER I NVEST CIENT & 40 & 117 & 19 & 6 & 1 & & 7 & & 2 & 2 & 2 & 1 \\
\hline USA & UNIV TEXAS & 23 & 18 & 4 & 14 & 2 & 1 & 5 & 1 & 5 & & 2 & \\
\hline USA & $\begin{array}{l}\text { HARVARD SMITHSONIAN CTR } \\
\text { ASTROPHYS }\end{array}$ & & 143 & & 1 & & & & 6 & & & & 2 \\
\hline FRANCE & UNIV PARIS & 27 & 6 & 5 & 20 & 8 & 2 & & 2 & & & & \\
\hline USA & UNIV WISCONSIN & 18 & 49 & & 7 & 1 & 1 & & 1 & & 1 & & \\
\hline USA & UNIV CALIF BERKELEY & 4 & 33 & 1 & 4 & 1 & 1 & & 9 & 1 & & & \\
\hline FRANCE & CTR NATL RECH SCl & 14 & 7 & 16 & 7 & 2 & 1 & & 6 & & & & \\
\hline USA & UNIV ARIZONA & 5 & 21 & & 2 & 1 & 1 & & & & & & 1 \\
\hline CUBA & UNIV LA HABANA & 14 & & 17 & & & 10 & 2 & & 31 & 6 & & \\
\hline CHILE & UNIV CHILE & 4 & 69 & & 4 & & & & & & & & 2 \\
\hline SPAIN & UNIV BARCELONA & 6 & 40 & 7 & 4 & 6 & & & & & & & 1 \\
\hline USA & CALTECH & 1 & 63 & 6 & 7 & & 8 & & & & & & \\
\hline USA & UNIV CALIF SAN DIEGO & 16 & 8 & 6 & 3 & 5 & 2 & 1 & & 16 & & & \\
\hline POLAND & MARIE CURIE SKLODOWSKA UNIV & 7 & & 1 & & & & & & & & & \\
\hline SPAIN & INST ASTROFIS CANARIAS & & 89 & & 1 & & & & & & & & \\
\hline CANADA & UNIV TORONTO & 3 & 17 & 1 & & & & & & & & 1 & \\
\hline SPAIN & UNIV AUTONOMA MADRID & 59 & 7 & 9 & 1 & & & 1 & & & 1 & & \\
\hline ENGLAND & UNIV SUSSEX & 56 & 4 & 6 & 8 & & & & & & & & \\
\hline USA & TEXAS A\&M UNIV & 18 & & 17 & 1 & 1 & 1 & & & & & & \\
\hline USA & OAK RIDGE NATL LAB & 62 & & & 15 & & & & 6 & & & & \\
\hline RUSSIA & RUSSIAN ACAD SCl & 3 & 19 & 6 & 2 & 3 & & & 1 & 2 & & & \\
\hline USA & HARVARD UNIV & 4 & 8 & 2 & & & 2 & & 2 & & & & \\
\hline USA & UNIV MARYLAND & 2 & 6 & 1 & 13 & 3 & & & 1 & & & & \\
\hline USA & UNIV CALIF LOS ANGELES & 7 & 5 & & & 1 & & & & & & & \\
\hline ENGLAND & UNIV MANCHESTER & & 69 & & 2 & & & & & 7 & & & \\
\hline ENGLAND & UNIV LONDON & 6 & 6 & 2 & 2 & 1 & 5 & 3 & & 2 & 4 & & \\
\hline UKRAINE & NATL ACAD SCI UKRAINE & 4 & 3 & & 8 & & & 1 & & & 3 & & \\
\hline USA & UNIV COLORADO & & 26 & 4 & 1 & 2 & 1 & 6 & 5 & & & & \\
\hline USA & UNIV FLORIDA & 3 & 2 & 4 & 3 & 1 & & 2 & & & & & \\
\hline USA & LOUISIANA STATE UNIV & & 1 & & 33 & 1 & & & & & & & \\
\hline ITALY & CONS NAZ RICER & & 37 & 1 & & & & & & & & & \\
\hline RUSSIA & MOSCOW MV LOMONOSOV STATE UNIV & 4 & 10 & 6 & 12 & 1 & 1 & & & 6 & & & \\
\hline ENGLAND & UNIV CAMBRIDGE & 8 & 16 & 11 & 2 & & 1 & & & & 1 & & \\
\hline USA & UNIV CALIF IRVINE & 7 & 3 & 6 & & & 3 & & & & & & \\
\hline SPAIN & UNIV COMPLUTENSE MADRID & 5 & 12 & 11 & 1 & 4 & 1 & 4 & & & 1 & & \\
\hline USA & STATE UNIVERSITY NEW YORK & 8 & 4 & 4 & & 1 & & & & & & & \\
\hline SPAIN & UNIV SEVILLA & 16 & 1 & 1 & 28 & 4 & & & 11 & & & & \\
\hline USA & NASA & 1 & 22 & & 5 & & & & & & & & \\
\hline USA & STANFORD UNIV & 5 & & & 2 & & 1 & & 1 & 2 & & & \\
\hline USA & PENN STATE UNIV & 1 & 4 & & 24 & & & & & & & & \\
\hline USA & UNIV MICHIGAN & 7 & 28 & & 4 & & 1 & & & & & & \\
\hline ENGLAND & UNIV OXFORD & 14 & 8 & 2 & 5 & 2 & 4 & 2 & 1 & & & 1 & \\
\hline USA & UNIV WASHINGTON & 4 & 19 & & 1 & 1 & 1 & & 1 & & & & \\
\hline CANADA & MCGILL UNIV & 7 & & & & & & 1 & & 1 & & & \\
\hline USA & UNIV MINNESOTA & 1 & 7 & 1 & 4 & 2 & 1 & & 3 & & & & \\
\hline USA & UNIV ILLINOIS & 7 & 11 & 3 & 2 & 1 & & 1 & & & & & \\
\hline CANADA & UNIV MONTREAL & 1 & 28 & & 2 & 1 & 1 & & 4 & & & & \\
\hline USA & YALE UNIV & 4 & 1 & & 21 & & & & & & & & \\
\hline ARGENTINA & UNIV NATL LA PLATA & 6 & 7 & & 31 & & & & & & & & \\
\hline
\end{tabular}

FUENTE: Laboratorio de Redes, Departamento de Modelación Matemática de Sistemas Sociales, IIMAS-UNAM, 2005.

Tabla 5. Colaboración SIC-UNAM con instituciones del extranjero. Área Ciencias Físico Matemáticas 
REDES- Revista hispana para el análisis de redes sociales

Vol.17,\#1, diciembre 2009

http: //revista-redes.rediris.es

\begin{tabular}{|c|c|c|c|c|c|c|c|c|c|c|c|}
\hline País & Institución & $\underline{0}$ & 悲 & $\stackrel{\varepsilon}{\underline{\varrho}}$ & $\underline{\underline{m}}$ & $\underline{\varrho}$ & $\underline{\underline{ }}$ & $\underset{\underline{U}}{\vec{U}}$ & U্য & $\underline{\Sigma}$ & 岕 \\
\hline SPAIN & CONSEJ O SUPER I NVEST CIENT & 8 & & 1 & 3 & 5 & 2 & 12 & 5 & 1 & \\
\hline USA & UNIV TEXAS & 4 & 5 & 4 & 6 & 3 & 2 & & 3 & 2 & \\
\hline USA & HARVARD SMITHSONIAN CTR ASTROPHYS & & & & & & & & & & \\
\hline FRANCE & UNIV PARIS & 6 & & & & 1 & 1 & & & & \\
\hline USA & UNIV WISCONSIN & & & 1 & 13 & 2 & 1 & & 4 & & \\
\hline USA & UNIV CALIF BERKELEY & 3 & 1 & 4 & 2 & 9 & 15 & & & & \\
\hline FRANCE & CTR NATL RECH SCl & 9 & 9 & 3 & 2 & 1 & & & 6 & & \\
\hline USA & UNIV ARIZONA & 3 & 6 & 3 & 13 & 14 & 13 & & & 2 & 1 \\
\hline CUBA & UNIV LA HABANA & 2 & & 3 & 1 & 1 & & 7 & & & \\
\hline CHILE & UNIV CHILE & & 1 & 7 & 8 & & 2 & & & & \\
\hline SPAIN & UNIV BARCELONA & 1 & 1 & 2 & & & & 5 & 1 & & \\
\hline USA & CALTECH & & 1 & 1 & & 1 & 1 & & & & \\
\hline USA & UNIV CALIF SAN DIEGO & & 2 & 1 & 3 & 1 & 5 & 3 & 1 & & \\
\hline POLAND & MARIE CURIE SKLODOWSKA UNIV & 87 & & & & & & & & & \\
\hline SPAIN & INST ASTROFIS CANARIAS & & & & & & & & & & \\
\hline CANADA & UNIV TORONTO & 42 & 6 & & 1 & 3 & & & & & \\
\hline SPAIN & UNIV AUTONOMA MADRID & 8 & & 3 & 1 & & & & & 1 & \\
\hline ENGLAND & UNIV SUSSEX & & & & 1 & & 1 & 1 & & & 1 \\
\hline USA & TEXAS A\&M UNIV & & & & 1 & 6 & 2 & 14 & & & \\
\hline USA & OAK RIDGE NATL LAB & & & 1 & & & & & 1 & & \\
\hline RUSSIA & RUSSIAN ACAD SCI & 10 & 3 & 2 & 2 & 2 & 1 & & 2 & & \\
\hline USA & HARVARD UNIV & 10 & 4 & 17 & 7 & 2 & 6 & & & 1 & \\
\hline USA & UNIV MARYLAND & 1 & 1 & 1 & 8 & & 7 & 5 & 1 & 4 & \\
\hline USA & UNIV CALIF LOS ANGELES & & 11 & 2 & 3 & 1 & 1 & & 1 & & \\
\hline ENGLAND & UNIV MANCHESTER & & 1 & 1 & & & & & & & \\
\hline ENGLAND & UNIV LONDON & 4 & 1 & 2 & 2 & 3 & 4 & & 1 & 3 & \\
\hline UKRAINE & NATL ACAD SCI UKRAINE & 62 & & & & & & & & & \\
\hline USA & UNIV COLORADO & & 1 & & 4 & 5 & 4 & & & & \\
\hline USA & UNIV FLORIDA & & & & 8 & 18 & 9 & 2 & & 5 & \\
\hline USA & LOUISIANA STATE UNIV & 13 & & 1 & 1 & 1 & & 12 & & & \\
\hline ITALY & CONS NAZ RICER & 1 & & 2 & 24 & & 1 & & 1 & & \\
\hline RUSSIA & MOSCOW MV LOMONOSOV STATE UNIV & 21 & & & & & & & & & \\
\hline ENGLAND & UNIV CAMBRIDGE & 7 & 2 & 1 & 2 & & 4 & 1 & & 1 & \\
\hline USA & UNIV CALIF IRVINE & 2 & 6 & & 1 & & 7 & & & 17 & \\
\hline SPAIN & UNIV COMPLUTENSE MADRID & 2 & & & & & & & & & \\
\hline USA & STATE UNIVERSITY NEW YORK & & 4 & 1 & 2 & & & 1 & & & \\
\hline SPAIN & UNIV SEVILLA & & & & 4 & & 1 & 3 & & 1 & \\
\hline USA & NASA & 1 & & & & & 3 & & & & \\
\hline USA & STANFORD UNIV & & 1 & 6 & 14 & 4 & 9 & 1 & & & \\
\hline USA & PENN STATE UNIV & 1 & 2 & 1 & 2 & 2 & 5 & & 1 & & \\
\hline USA & UNIV MICHIGAN & & 3 & 1 & & 3 & 2 & & 1 & & \\
\hline ENGLAND & UNIV OXFORD & 2 & 2 & & 2 & 3 & 4 & & 1 & & \\
\hline USA & UNIV WASHINGTON & 7 & & 1 & 1 & & 8 & 1 & & 1 & \\
\hline CANADA & MCGILL UNIV & & 2 & 12 & 1 & 3 & 2 & & & 1 & \\
\hline USA & UNIV MI NNESOTA & & 1 & 1 & 2 & 4 & 3 & & 6 & & \\
\hline USA & UNIV I LLINOIS & 1 & 2 & 1 & 3 & 1 & 2 & & 1 & & \\
\hline CANADA & UNIV MONTREAL & & 1 & & 2 & & & & & & \\
\hline USA & YALE UNIV & & 1 & 6 & 1 & 3 & 4 & & & 1 & \\
\hline ARGENTINA & UNIV NATL LA PLATA & & & & & & & 1 & & & \\
\hline
\end{tabular}

FUENTE: Laboratorio de Redes, Departamento de Modelación Matemática de Sistemas Sociales, IIMAS-UNAM, 2005.

Tabla 6. Colaboración SIC-UNAM con instituciones del extranjero. Área Ciencias Químico-Biológicas y de la Salud. 
REDES- Revista hispana para el análisis de redes sociales

Vol.17,\#1, diciembre 2009

http: //revista-redes.rediris.es

\begin{tabular}{|c|c|c|c|c|c|c|c|}
\hline país & Institución & $\underline{\underline{\Xi}}$ & $=$ & $\underline{\Xi}$ & 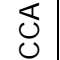 & 임 & ن \\
\hline SPAIN & CONSEJ O SUPER INVEST CIENT & & 5 & & & & \\
\hline USA & UNIV TEXAS & 4 & 2 & 11 & & 1 & 1 \\
\hline USA & HARVARD SMITHSONIAN CTR ASTROPHYS & & & & & & \\
\hline FRANCE & UNIV PARIS & 5 & 2 & 17 & & 3 & \\
\hline USA & UNIV WISCONSIN & 7 & 1 & 3 & & & \\
\hline USA & UNIV CALIF BERKELEY & 2 & 9 & 5 & 2 & 1 & \\
\hline FRANCE & CTR NATL RECH SCl & 10 & & 5 & & & 1 \\
\hline USA & UNIV ARIZONA & 2 & & 13 & 1 & & \\
\hline CUBA & UNIV LA HABANA & 2 & 12 & & & & \\
\hline CHILE & UNIV CHILE & 12 & 1 & & & & \\
\hline SPAIN & UNIV BARCELONA & 10 & & 4 & & 1 & 2 \\
\hline USA & CALTECH & 13 & 2 & 4 & 3 & 1 & \\
\hline USA & UNIV CALIF SAN DIEGO & 5 & 4 & & & & \\
\hline POLAND & MARIE CURIE SKLODOWSKA UNIV & & & & & & \\
\hline SPAIN & INST ASTROFIS CANARIAS & & & & & & \\
\hline CANADA & UNIV TORONTO & 2 & & & & & \\
\hline SPAIN & UNIV AUTONOMA MADRID & & & & & & \\
\hline ENGLAND & UNIV SUSSEX & & & & & & \\
\hline USA & TEXAS A\&M UNIV & 3 & & 3 & & & \\
\hline USA & OAK RIDGE NATL LAB & & & & & & \\
\hline RUSSIA & RUSSIAN ACAD SCI & 17 & & 1 & 1 & & \\
\hline USA & HARVARD UNIV & & & 2 & & & 1 \\
\hline USA & UNIV MARYLAND & 2 & & & & & \\
\hline USA & UNIV CALIF LOS ANGELES & 18 & 1 & 2 & 2 & & \\
\hline ENGLAND & UNIV MANCHESTER & & 1 & & & & \\
\hline ENGLAND & UNIV LONDON & 11 & & & & & \\
\hline UKRAINE & NATL ACAD SCI UKRAINE & 1 & & & & & \\
\hline USA & UNIV COLORADO & 7 & 1 & 1 & 5 & & \\
\hline USA & UNIV FLORIDA & & & & 1 & 1 & \\
\hline USA & LOUISIANA STATE UNIV & 1 & & & & & \\
\hline ITALY & CONS NAZ RICER & 2 & & 1 & & & 1 \\
\hline RUSSIA & MOSCOW MV LOMONOSOV STATE UNIV & & 1 & 1 & & & \\
\hline ENGLAND & UNIV CAMBRIDGE & 2 & & & & & \\
\hline USA & UNIV CALIF IRVINE & & & 1 & 1 & & \\
\hline SPAIN & UNIV COMPLUTENSE MADRID & 6 & 2 & 1 & & 4 & 1 \\
\hline USA & STATE UNIVERSITY NEW YORK & 10 & 1 & & & & \\
\hline SPAIN & UNIV SEVILLA & & & & & & \\
\hline USA & NASA & 14 & & & 4 & & \\
\hline USA & STANFORD UNIV & 3 & & 1 & & 2 & \\
\hline USA & PENN STATE UNIV & & & & 1 & & \\
\hline USA & UNIV MICHIGAN & 6 & & 1 & & & \\
\hline ENGLAND & UNIV OXFORD & & & & & & \\
\hline USA & UNIV WASHINGTON & 2 & & & & 1 & \\
\hline CANADA & MCGILL UNIV & & & 2 & & & \\
\hline USA & UNIV MI NNESOTA & 2 & 1 & & & 1 & \\
\hline USA & UNIV I LLINOIS & 1 & & 1 & & & \\
\hline CANADA & UNIV MONTREAL & & & & & & \\
\hline USA & YALE UNIV & & & 1 & & & \\
\hline ARGENTINA & UNIV NATL LA PLATA & & & & & & \\
\hline
\end{tabular}

FUENTE: Laboratorio de Redes, Departamento de Modelación Matemática de Sistemas Sociales, IIMAS-UNAM, 2005.

Tabla 7. Colaboración SIC-UNAM con instituciones del extranjero. Área Ciencias de la Tierra e Ingenierías 
REDES- Revista hispana para el análisis de redes sociales

Vol.17,\#1, diciembre 2009

http: //revista-redes.rediris.es

\section{Colaboración entre entidades}

Las entidades del Subsistema publicaron 1271 artículos en colaboración con otras entidades del SIC, lo que representa el $6.7 \%$ del total de artículos publicados. El número mayor de entidades participantes en un artículo es de tres

Entre las entidades del Subsistema la mayor colaboración se da entre el Instituto de Física y el Instituto de Investigación en Materiales con un total de 151 artículos. En la Tabla 8 se muestra la colaboración entre entidades, los valores en la diagonal de la matriz son el número total de artículos publicados por cada entidad. Hay 71 artículos en que participaron tres entidades. En la Figura 4 se puede observar la red de colaboración entre las entidades del SIC.

\begin{tabular}{|c|c|c|c|c|c|c|c|c|c|c|c|c|c|c|c|c|c|c|c|c|c|c|c|c|c|c|c|c|}
\hline & $\Xi$ & $\vdots$ & $\underset{ِ}{Z}$ & ט & $\begin{array}{l}\mathrm{n} \\
\mathrm{U} \\
\mathrm{U}\end{array}$ & $\sum_{\mathcal{U}}^{U}$ & 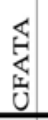 & 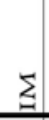 & $\sum_{3}^{\infty}$ & 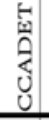 & $\leqq$ & 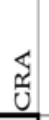 & d & $\underset{\Xi}{U}$ & 9 & 9 & $\sum_{0}^{1}$ & 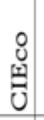 & 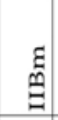 & $\ddot{\theta}$ & $\begin{array}{l}0 \\
0 \\
U\end{array}$ & $\underset{\mathbf{z}}{\mathrm{z}}$ & $\stackrel{0}{0}$ & $\bar{\Xi}$ & $\underset{U}{\bigcup}$ & $\bigcup^{\infty}$ & $\begin{array}{l}0 \\
U\end{array}$ & I \\
\hline IF & 3034 & 151 & 123 & 5 & 22 & 29 & 4 & 5 & 11 & 24 & 8 & & 28 & 10 & & 3 & & & 6 & & & & 2 & 4 & 1 & & & 7 \\
\hline IIM & 151 & 1347 & 28 & 18 & 3 & 5 & 3 & & & 12 & & & 42 & 6 & & & & & & 1 & & & & 5 & 2 & & & 6 \\
\hline ICN & 123 & 28 & 1164 & & 38 & 2 & & 15 & 14 & 14 & 29 & & 13 & & & & & & & & & & 4 & & 4 & & & \\
\hline CIE & 5 & 18 & & 384 & 4 & & & 3 & & 5 & & & & & & & & & & 1 & & & & 2 & & & 3 & 2 \\
\hline $\mathrm{CCF}$ & 22 & 3 & 38 & 4 & 284 & & 1 & 8 & 4 & 1 & 2 & & 3 & 3 & & & & & & & & & & & & & & \\
\hline CCMC & 29 & 5 & 2 & & & 281 & & & & & 2 & & & & & & & & & & & & 2 & & & & & \\
\hline CFATA & 4 & 3 & & & 1 & & 52 & 1 & & 1 & & & & & & & & & & & & & & & & & & \\
\hline $\mathrm{IM}$ & 5 & & 15 & 3 & 8 & & 1 & 720 & 8 & 1 & & & & & & & & & & & & & 2 & & & & & \\
\hline IIMAS & 11 & & 14 & & 4 & & & 8 & 514 & 1 & & & 1 & 1 & 5 & 1 & 1 & & 4 & & 2 & & 5 & 1 & 1 & 1 & & 7 \\
\hline CCADET & 24 & 12 & 14 & 5 & 1 & & 1 & 1 & 12 & 270 & 17 & & 2 & 3 & & 1 & & & 7 & 9 & & 2 & 3 & & & & & 8 \\
\hline IA & 8 & & 29 & & 2 & 2 & & & & 17 & 1716 & 2 & & & & & & & & & & & 5 & & 2 & & & \\
\hline CRA & & & & & & & & & & & 2 & 6 & & & & & & & & & & & & & & & & \\
\hline IQ & 28 & 42 & 13 & & 3 & & & & 1 & 2 & & & 1832 & 26 & 57 & 7 & 1 & & 16 & 10 & & 2 & & 1 & & & & \\
\hline IFC & 10 & 6 & & & 3 & & & & 1 & 3 & & & 26 & 1463 & 6 & 1 & 2 & & 52 & 27 & 8 & 14 & & & & & & 1 \\
\hline IB & & & & & & & & & 5 & & & & 57 & 6 & 983 & 35 & 13 & & 9 & & 3 & & & 5 & 1 & 2 & & \\
\hline IE & 3 & & & & & & & & 1. & 1 & & & 7 & 1 & 35 & 719 & & 1 & 11 & 4 & 3 & 1 & 2 & 3 & 2 & 11 & & 5 \\
\hline ICMyL & & & & & & & & & 1 & & & & 1 & 2 & 13 & & 611 & & 1 & 1 & 1 & 3 & 4 & 3 & & & & \\
\hline CIEco & & & & & & & & & & & & & & & & 1 & & 11 & & & & & & & & 1 & & \\
\hline IIBm & 6 & & & & & & & & 4 & 7 & & & 16 & 52 & 9 & 11 & 1 & & 1369 & 30 & 6 & 15 & 1 & & 1 & & & 1 \\
\hline IBt & & 1 & & 1 & & & & & & 9 & & & 10 & 27 & & 4 & 1 & & 30 & 1037 & 19 & & & & 1 & & & 1 \\
\hline CCG & & & & & & & & & 2 & & & & & 8 & 3 & 3 & 1 & & 6 & 19 & 300 & 1 & & & & & & 1 \\
\hline $\mathrm{INr}$ & & & & & & & & & & 2 & & & 2 & 14 & & 1 & 3 & & 15 & & 12 & 274 & & & & & & \\
\hline IGf & 2 & & 4 & & & 2 & & 2 & 5 & 3 & 5 & & & & & 2 & 4 & & 1 & & & & 811 & 41 & 9 & 5 & 4 & 49 \\
\hline IGl & 4 & 5 & & 2 & & & & & 1 & & & & 1 & & 5 & 3. & 3 & & & & & & 41 & 367 & & 3 & 5 & 1 \\
\hline $\mathrm{CCA}$ & 1 & 2 & 4 & & & & & & 1 & & 2 & & & & 1 & 2 & & & 1 & 1 & & & 9 & & 235 & 5 & & \\
\hline $\mathrm{IGg}$ & & & & & & & & & 1. & & & & & & 2 & 11 & & 1 & & & & & 5 & \begin{tabular}{|l|}
3 \\
\end{tabular} & 5 & 91 & & \\
\hline CG & & & & 3 & & & & & & & & & & & & & & & & & & & 4 & 5 & & & 41 & \\
\hline II & 7 & 6 & & 2 & & & & & 7 & 8 & & & & 1 & & 5 & & & 1 & 1 & 1 & & 49 & 1 & & & & 517 \\
\hline
\end{tabular}

FUENTE: Laboratorio de Redes, Departamento de Modelación Matemática de Sistemas Sociales, IIMAS-UNAM, 2005.

Tabla 8. Colaboración entre entidades del SIC-UNAM. 
REDES- Revista hispana para el análisis de redes sociales

Vol.17,\#1, diciembre 2009

http: //revista-redes.rediris.es

Ciencias de la Tierra

e Ingenierías

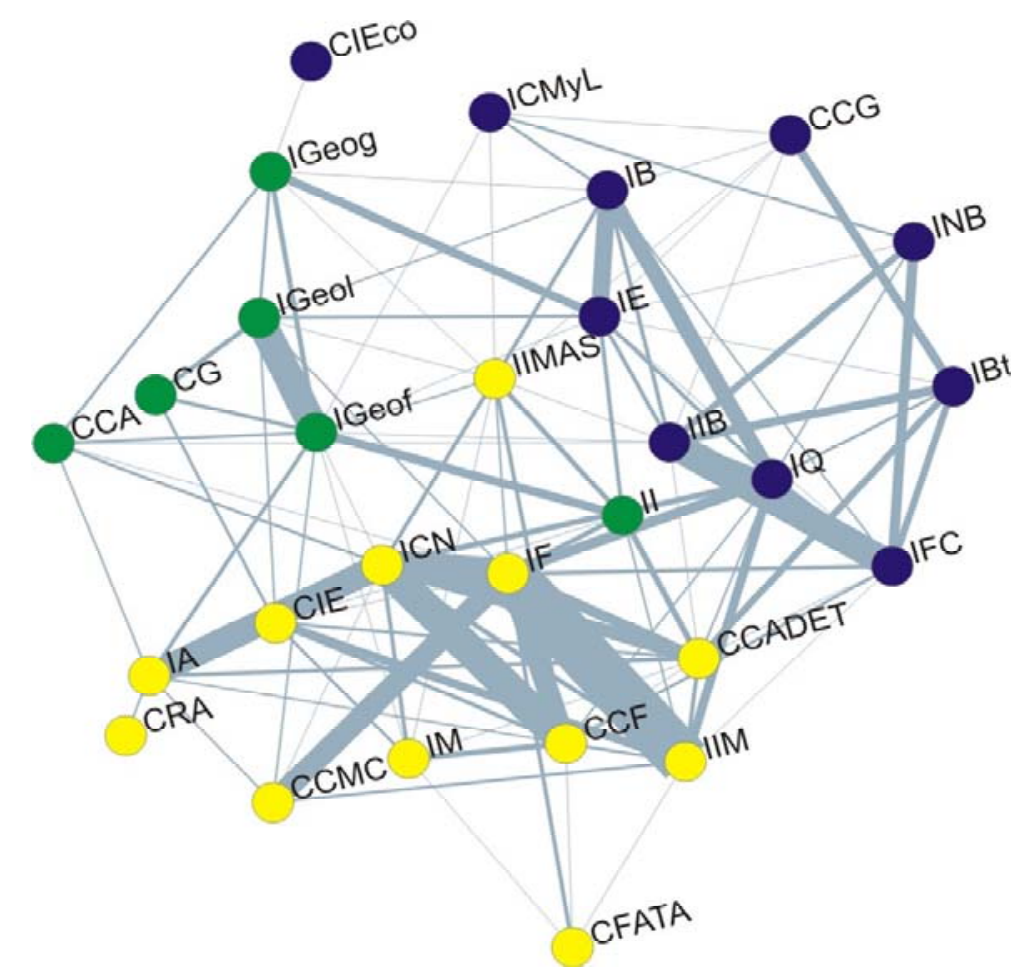

Ciencias Químico Biológicas y de la Salud

Ciencias Físico Matemáticas

FUENTE: Laboratorio de Redes, Departamento de Modelación Matemática de Sistemas Sociales, IIMAS-UNAM, 2005.

Figura 4. Colaboración entre entidades del SIC-UNAM.

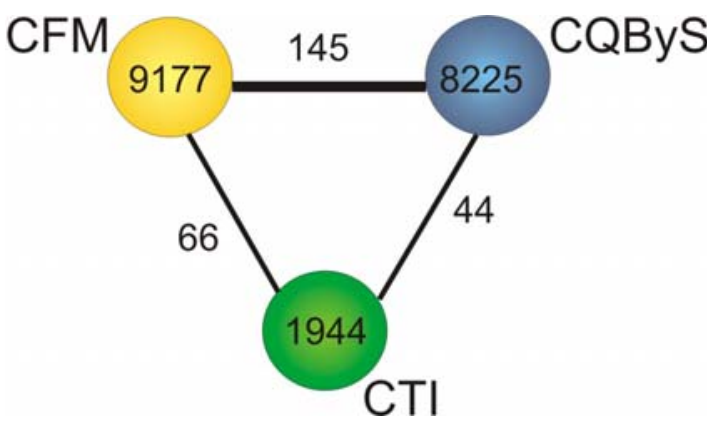

FUENTE: Laboratorio de Redes, Departamento de Modelación Matemática de Sistemas Sociales, IIMAS-UNAM, 2005.

Figura 5. Colaboración entre áreas del SIC-UNAM.

De la Figura 5 queremos anotar que el $6.2 \%$ de los artículos (566) publicados por el área de las Ciencias Físico-Matemáticas (CFM) corresponden a aquellos que se encuentran fuera de la diagonal de la Tabla 8 y sin repeticiones; en el mismo caso se encuentra el área de las Ciencias Químico- Biológicas y de la Salud (CQByS) con un 4.4\% (262 artículos), finalmente en el caso del área de las Ciencias de la Tierra y las Ingenierías (CTI) el $5.9 \%$ de los artículos (114) es el que se encuentra fuera de la diagonal. El total de artículos publicados en colaboración entre las tres áreas es de 255 y representa el $1.33 \%$ del total. 
REDES- Revista hispana para el análisis de redes sociales

Vol.17,\#1, diciembre 2009

http: // revista-redes.rediris.es

\section{Artículos por área}

En la Tabla 9 se muestra el total de artículos por área de conocimiento, de las diversas entidades que pertenecen al SIC. Cabe señalar que el número mayor de artículos se publican en el área de Physical, Chemical \& Earth Sciences.

\begin{tabular}{|l|r|}
\hline \multicolumn{1}{|c|}{ Área } & Total \\
\hline Physical, Chemical \& Herat Sciences & 9858 \\
\hline Life Sciences & 4497 \\
\hline $\begin{array}{l}\text { Agriculture, Biology \& Environmental } \\
\text { Sciences }\end{array}$ & 3280 \\
\hline Engineering, Computing \& Technology & 2028 \\
\hline Clinical Medicine & 344 \\
\hline Multidisciplinary & 272 \\
\hline Social \& Behavioral Sciences & 195 \\
\hline Arts \& Humanities & 18 \\
\hline
\end{tabular}

FUENTE: Laboratorio de Redes, Departamento de Modelación Matemática de Sistemas Sociales, IIMAS-UNAM, 2005.

Tabla 9. Artículos por área ISI-Thomson. SIC-UNAM

En la Tablas 10, 11 y 12 se muestra el total de artículos por área de conocimiento, y su distribución por cada una de las entidades que pertenecen al SIC. Cabe señalar que el número mayor de artículos se publican en el área de Physical, Chemical \& Earth Sciences.

\begin{tabular}{|c|c|c|c|c|c|c|c|c|}
\hline & 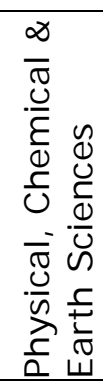 & 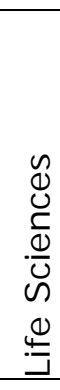 & 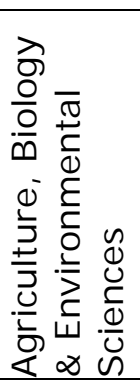 & 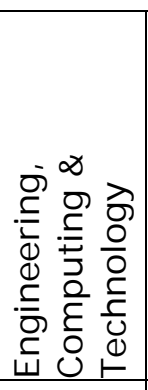 & 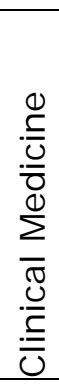 & 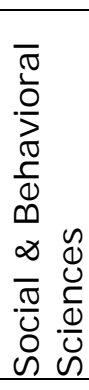 & 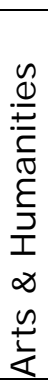 & 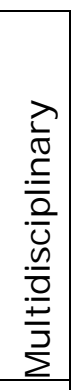 \\
\hline IF & 2599 & 56 & 51 & 692 & 17 & 11 & & 78 \\
\hline $\mathrm{IIM}$ & 1104 & 20 & 10 & 427 & 3 & & & 11 \\
\hline ICN & 1035 & 39 & 20 & 35 & 1 & & & 14 \\
\hline $\mathrm{ClE}$ & 279 & 6 & 3 & 191 & & 5 & & 7 \\
\hline CCF & 251 & 6 & & 41 & & & & 6 \\
\hline CCMC & 260 & 1 & 1 & 91 & & & & 4 \\
\hline CFATA & 36 & & 2 & 24 & 2 & & & 7 \\
\hline$I M$ & 460 & 10 & 1 & 31 & 3 & 3 & 2 & 8 \\
\hline IIMAS & 271 & 30 & 24 & 135 & 15 & 20 & 3 & 15 \\
\hline CCADET & 164 & 25 & 5 & 131 & 3 & 5 & 1 & 14 \\
\hline IA & 1594 & 1 & 1 & 24 & & 1 & & 4 \\
\hline $\mathrm{R} /$ & & $\perp$ & & & & & & \\
\hline
\end{tabular}

FUENTE: Laboratorio de Redes, Departamento de Modelación Matemática de Sistemas Sociales, IIMAS-UNAM, 2005.

Tabla 10. Artículos por área ISI-Thomson. SIC-Área Ciencias Físico Matemáticas 
REDES- Revista hispana para el análisis de redes sociales

Vol.17, \#1, diciembre 2009

http: // revista-redes.rediris.es

\begin{tabular}{|c|c|c|c|c|c|c|c|c|}
\hline & 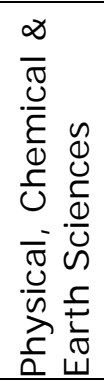 & 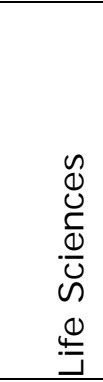 & 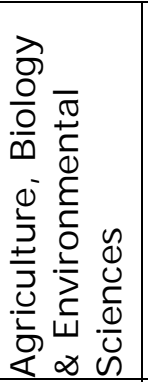 & 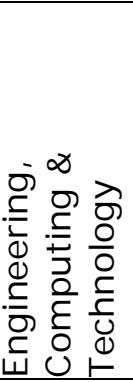 & 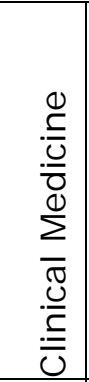 & 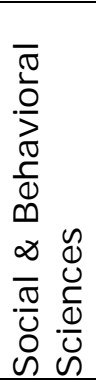 & 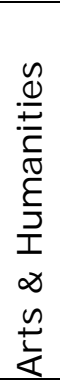 & 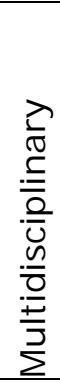 \\
\hline IQ & 1199 & 541 & 317 & 19 & 6 & & & 12 \\
\hline IFC & 12 & 1274 & 87 & 7 & 62 & 15 & & 12 \\
\hline IB & 18 & 156 & 876 & 2 & 5 & 2 & & 11 \\
\hline IE & 14 & 106 & 635 & 11 & 2 & 14 & 3 & 29 \\
\hline ICMyL & 51 & 66 & 525 & 9 & 3 & & & 2 \\
\hline ClEco & & 1 & 11 & & & & & \\
\hline IIBm & 15 & 1075 & 135 & 6 & 186 & 63 & 2 & 18 \\
\hline IBt & 20 & 902 & 313 & 14 & 23 & 4 & & 13 \\
\hline CCG & 2 & 245 & 102 & & 2 & & 2 & 7 \\
\hline $\mathrm{INr}$ & 1 & 215 & 17 & 2 & 23 & 33 & & 2 \\
\hline
\end{tabular}

FUENTE: Laboratorio de Redes, Departamento de Modelación Matemática de Sistemas Sociales, IIMAS-UNAM, 2005

Tabla 11. Artículos por área ISI-Thomson. SIC-Área Ciencias Químico-Biológicas y de la Salud

\begin{tabular}{|c|c|c|c|c|c|c|c|c|}
\hline & 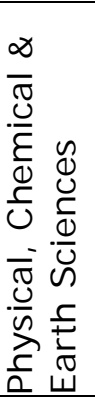 & 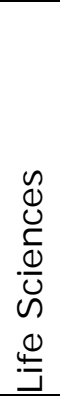 & 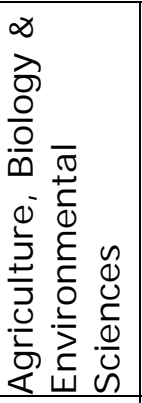 & 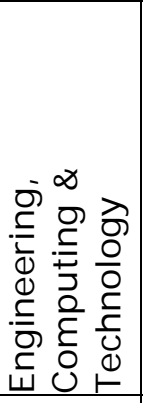 & 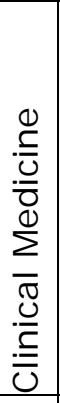 & 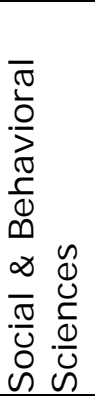 & 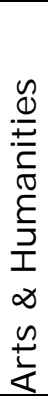 & 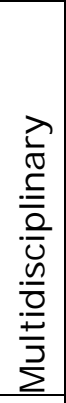 \\
\hline IGf & 649 & 9 & 43 & 43 & & 6 & 3 & 8 \\
\hline $\mid \mathrm{GI}$ & 261 & 3 & 70 & 15 & 1 & 1 & & 18 \\
\hline CCA & 113 & 30 & 90 & 9 & 5 & 1 & & 4 \\
\hline $\mathrm{IGg}$ & 39 & 1 & 29 & 8 & & 10 & 1 & 4 \\
\hline CG & 40 & 1 & 1 & & & & & \\
\hline II & 131 & 8 & 119 & 225 & & 6 & 1 & 4 \\
\hline
\end{tabular}

FUENTE: Laboratorio de Redes, Departamento de Modelación Matemática de Sistemas Sociales, IIMAS-UNAM, 2005.

Tabla 12. Artículos por área ISI-Thomson. SIC-Área Ciencias de la Tierra e Ingeniería. 
REDES- Revista hispana para el análisis de redes sociales

Vol.17, \#1, diciembre 2009

http://revista-redes.rediris.es

\section{Artículos por Revista}

Los investigadores de las entidades del SIC han publicado artículos en 2387 revistas. En la Tabla 13 se muestra, por área, el número de revistas donde han sido publicados los artículos de los investigadores afiliados a entidades del SIC, hay revistas que están clasificados en más de un área.

\begin{tabular}{|l|r|}
\hline \multicolumn{1}{|c|}{ Area } & Total \\
\hline Physical, Chemical \& Earth Sciences & 712 \\
\hline Life Sciences & 655 \\
\hline Agriculture, Biology \& Environmental Sciences & 483 \\
\hline Engineering, Computing \& Technology & 352 \\
\hline Clinical Medicine & 143 \\
\hline Social \& Behavioral Sciences & 60 \\
\hline Multidisciplinary & 52 \\
\hline Arts \& Humanities & 11 \\
\hline
\end{tabular}

FUENTE: Laboratorio de Redes, Departamento de Modelación Matemática de Sistemas Sociales, IIMAS-UNAM, 2005.

Tabla 13. Revistas por área SIC-UNAM.

En las Tablas 14, 15 y 16 se muestra la distribución del número de artículos publicados respecto a las entidades del SIC por revista, para un total mayor a 50 artículos por revista. 
REDES- Revista hispana para el análisis de redes sociales

Vol.17,\#1, diciembre 2009

http: //revista-redes.rediris.es

\begin{tabular}{|c|c|c|c|c|c|c|c|c|c|c|c|c|c|}
\hline NOMBRE DE REVISTA & Total & $\underline{=}$ & $\underline{\Sigma}$ & $\underline{z}$ & $\frac{\omega}{U}$ & U & $\sum_{U}^{U}$ & $\underset{⿱ 亠 凶}{\mathbb{4}}$ & $\underline{\Sigma}$ & $\sum_{\Sigma}^{n}$ & $\begin{array}{l}\text { 㟧 } \\
\text { 它 }\end{array}$ & $\leq$ & 寽 \\
\hline ASTROPHYS J & 436 & $\overline{1}$ & & 15 & & 2 & & & & & 1 & 415 & 4 \\
\hline REV MEX FIS & 397 & 185 & 66 & 92 & 11 & 11 & 13 & 1 & 2 & 7 & 21 & 11 & \\
\hline REV MEX ASTRON ASTR & 376 & 1 & & 8 & & 2 & & & & & 4 & 372 & 1 \\
\hline ASTRON ASTROPHYS & 325 & & & 8 & & & 1 & & & & 3 & 321 & \\
\hline PHYS REV B & 240 & 174 & 39 & 4 & 3 & 8 & 26 & & & & & & \\
\hline PHYTOCHEMISTRY & 183 & & & & & & & & & & & & \\
\hline ABSTR PAP AM CHEM S & 161 & 32 & 27 & 14 & & 1 & 1 & & 1 & 1 & 4 & & \\
\hline PHYS REV A & 153 & 98 & 9 & 26 & & 18 & & & 1 & 8 & 1 & & \\
\hline PHYS REV D & 152 & 38 & & 112 & & & & & 2 & 6 & & 8 & \\
\hline J PHYS A-MATH GEN & 144 & 68 & 2 & 36 & & 23 & 2 & & 21 & 11 & & 1 & \\
\hline B SEISMOL SOC AM & 131 & 7 & & & & & & & 1 & 10 & & & \\
\hline ACTA CRYSTALLOGR C & 126 & 2 & 3 & 3 & & & & & & & 1 & & \\
\hline J CHEM PHYS & 116 & 57 & 15 & 3 & 6 & 9 & 1 & & 2 & & & 2 & \\
\hline J BACTERIOL & 115 & & & & & & & & & & 1 & & \\
\hline MON NOT R ASTRON SOC & 115 & 1 & & 2 & & & & & & & 1 & 114 & \\
\hline PHYS REV E & 113 & 45 & 9 & 8 & 15 & 22 & 2 & & 5 & & & 2 & \\
\hline PHYS REV C & 112 & 49 & & 70 & & 9 & & & & & & & \\
\hline IAU SYMP & 102 & & & & & & & & & & & 102 & \\
\hline PHYS REV LETT & 100 & 54 & 4 & 22 & 3 & 12 & 3 & 1 & 1 & 2 & & 2 & \\
\hline ASTRON J & 97 & & & 4 & & & & & & & & 94 & \\
\hline BRAIN RES & 95 & & & & & & & & & 1 & 3 & & \\
\hline PHYSICA A & 93 & 58 & 13 & 5 & 2 & 5 & & & 2 & 1 & 1 & & \\
\hline J MATH PHYS & 91 & 29 & & 44 & & 6 & & & 7 & 23 & & & \\
\hline NUCL INSTRUM METH B & 89 & 86 & 2 & 5 & & 2 & & & & & & & \\
\hline REV BIOL TROP & 89 & & & & & & & & & & & & \\
\hline THIN SOLID FILMS & 84 & 37 & 40 & & 11 & 1 & 3 & & & & 2 & & \\
\hline BIOPHYS J & 77 & 3 & & & & 3 & & & & & & & \\
\hline J NEUROCHEM & 76 & & & & & & & & & & & & \\
\hline PHYS LETT A & 75 & 37 & 5 & 11 & & 9 & 3 & & & 10 & & 1 & \\
\hline FEBS LETT & 74 & & & & & & & & & & & & \\
\hline RADIAT PHYS CHEM & 73 & 25 & 9 & 56 & & & 1 & & & & & & \\
\hline SOL ENERG MAT SOL C & 70 & 5 & 10 & & 58 & & & & & & & & \\
\hline $\mathrm{J} \mathrm{BIOL}$ CHEM & 67 & & & & & & & & & & & & \\
\hline J PHYS-CONDENS MAT & 67 & 43 & 13 & 1 & 1 & 1 & 6 & & & & 1 & & \\
\hline GEOPHYS RES LETT & 66 & & & 2 & & & & & & 1 & 2 & & \\
\hline J APPL PHYS & 66 & 20 & 39 & 1 & 3 & 1 & 5 & & & & 2 & 1 & \\
\hline J VOLCANOL GEOTH RES & 66 & & & & 6 & & & & & & & & \\
\hline MATER LETT & 66 & 45 & 4 & & & 2 & 12 & & & 2 & 7 & & \\
\hline TOPOL APPL & 66 & & & & & & & & 66 & & & & \\
\hline ARCH MED RES & 65 & 1 & & & & & & & 2 & 2 & 1 & & \\
\hline J ORGANOMET CHEM & 65 & 1 & 2 & & & & & & & & & & \\
\hline ASTROPHYS SPACE SCI & 64 & & 1 & 7 & & & & & & & & 51 & \\
\hline MOL PHYS & 64 & 21 & 1 & 2 & 3 & 1 & & & & & & & \\
\hline WATER SCI TECHNOL & 64 & & & & 1 & & & & & & & & \\
\hline CHEM PHYS LETT & 62 & 39 & 1 & 7 & & 2 & 2 & 1 & 3 & & & & \\
\hline J NAT PROD & 62 & & & & & & & & & & & & \\
\hline AM J BOT & 61 & & & & & & & & & & & & \\
\hline INT J QUANTUM CHEM & 61 & 42 & 8 & 7 & & 4 & & & & & & & \\
\hline TECTONOPHYSICS & 61 & 4 & & & & & & & & 2 & & & \\
\hline J NEUROSCI RES & 60 & & & & & & & & & & & & \\
\hline GENE & 58 & & & & & & & & & & & & \\
\hline PHYSICA C & 57 & 26 & 38 & & & & 1 & & 1 & & & & \\
\hline CLASSICAL QUANT GRAV & 56 & 1 & & 54 & & & & & 1 & & & & \\
\hline J PARASITOL & 56 & & & & & & & & & & & & \\
\hline SOLID STATE COMMUN & 55 & 30 & 19 & 1 & 2 & & 7 & & & & & & \\
\hline BIOCHEM BIOPH RES CO & 54 & & & & & 1 & & & & & & & \\
\hline J HETEROCYCLIC CHEM & 54 & & & & & & & & & & & & \\
\hline PHYS LETT B & 54 & 24 & & 32 & & 2 & & & & & & 2 & \\
\hline PLANT PHYSIOL & 54 & 1 & & & & & & & & & 1 & & \\
\hline ANAL SCI & 53 & & & 1 & & & & & & & 2 & & \\
\hline J NON-CRYST SOLIDS & 53 & 24 & 34 & 1 & 2 & & & & & & & & \\
\hline J PHYS D APPL PHYS & 51 & 15 & 17 & 1 & 9 & 7 & & 1 & & & 4 & & \\
\hline
\end{tabular}

FUENTE: Laboratorio de Redes, Departamento de Modelación Matemática de Sistemas Sociales, IIMAS-UNAM, 2005.

Tabla 14. Artículos por revista SIC-UNAM. Área Ciencias Físico Matemáticas 
REDES- Revista hispana para el análisis de redes sociales

Vol.17,\#1, diciembre 2009

http: // revista-redes.rediris.es

\begin{tabular}{|c|c|c|c|c|c|c|c|c|c|c|c|}
\hline NOMBRE DE REVISTA & Total & $\underline{\sigma}$ & 花 & $\underline{\varrho}$ & $\underline{\underline{ }}$ & $\underset{\underline{U}}{\vec{\lambda}}$ & 岕 & $\stackrel{\varepsilon}{\underline{\varepsilon}}$ & 䕎 & ن & $\sum_{\underline{z}}$ \\
\hline ASTROPHYS J & 436 & & & & & & & & & & \\
\hline REV MEX FIS & 397 & 8 & & & & 3 & & 4 & & & 1 \\
\hline REV MEX ASTRON ASTR & 376 & & & & & & & & & & \\
\hline ASTRON ASTROPHYS & 325 & & & & & & & & & & \\
\hline PHYS REV B & 240 & & & & & & & & & & \\
\hline PHYTOCHEMISTRY & 183 & 174 & 4 & 27 & 3 & & & & 2 & & \\
\hline ABSTR PAP AM CHEM S & 161 & 56 & 4 & 3 & & 6 & & 10 & 7 & & \\
\hline PHYS REV A & 153 & 1 & & & & & & & & & \\
\hline PHYS REV D & 152 & & & & & & & & & & \\
\hline J PHYS A-MATH GEN & 144 & & & & & & & & & & \\
\hline B SEISMOL SOC AM & 131 & & & & & & & & & & \\
\hline ACTA CRYSTALLOGR C & 126 & 123 & 1 & & & & & & & & \\
\hline J CHEM PHYS & 116 & 23 & & & & & & & & & \\
\hline BACTERIOL & 115 & & 28 & 2 & & 1 & & 18 & 34 & 51 & \\
\hline MON NOT R ASTRON SOC & 115 & & & & & & & & & & \\
\hline PHYS REV E & 113 & 9 & & & & & & & & & \\
\hline PHYS REV C & 112 & & & & & & & & & & \\
\hline IAU SYMP & 102 & & & & & & & & & & \\
\hline PHYS REV LETT & 100 & 1 & & & & & & & & & \\
\hline ASTRON J & 97 & & & & & & & & & & \\
\hline BRAIN RES & 95 & & 64 & & & & & 18 & 3 & & 13 \\
\hline PHYSICA A & 93 & 17 & & & 1 & & & & & & \\
\hline J MATH PHYS & 91 & & & & & & & & 1 & & \\
\hline NUCL I NSTRUM METH B & 89 & & 1 & & & & & & & & \\
\hline REV BIOL TROP & 89 & & & 27 & 3 & 56 & & & 1 & & \\
\hline THIN SOLID FILMS & 84 & & & & & & & & & & \\
\hline BIOPHYS J & 77 & 1 & 40 & & & & & 2 & 35 & & 1 \\
\hline J NEUROCHEM & 76 & & 60 & & & & & 14 & 5 & 1 & 1 \\
\hline PHYS LETT A & 75 & 3 & & & & & & & & & \\
\hline FEBS LETT & 74 & 3 & 27 & & & & & 1 & 44 & 2 & 2 \\
\hline RADIAT PHYS CHEM & 73 & & & & & & & & & & \\
\hline SOL ENERG MAT SOL C & 70 & & & & & & & & 1 & & \\
\hline $\mathrm{J} \mathrm{BIOL}$ CHEM & 67 & 2 & 38 & & 1 & & & 7 & 19 & 2 & 1 \\
\hline J PHYS-CONDENS MAT & 67 & 4 & & & & & & & & & \\
\hline GEOPHYS RES LETT & 66 & & & & & 1 & & & & & \\
\hline J APPL PHYS & 66 & & & & & & & & & & \\
\hline J VOLCANOL GEOTH RES & 66 & & & & & & & & & & \\
\hline MATER LETT & 66 & & & & & & & & & & \\
\hline TOPOL APPL & 66 & & & & & & & & & & \\
\hline ARCH MED RES & 65 & 2 & 15 & & 1 & 1 & & 30 & 9 & & 4 \\
\hline J ORGANOMET CHEM & 65 & 62 & & & & & & & & & \\
\hline ASTROPHYS SPACE SCI & 64 & & & & & & & & & & \\
\hline MOL PHYS & 64 & 36 & & & & & & & & & \\
\hline WATER SCI TECHNOL & 64 & & & & 2 & & & 1 & 1 & & \\
\hline CHEM PHYS LETT & 62 & 13 & & & & & & & & & \\
\hline J NAT PROD & 62 & 55 & 3 & 16 & 2 & & & & & 1 & \\
\hline AM J BOT & 61 & & 1 & 17 & 43 & & 1 & & 1 & & \\
\hline INT J QUANTUM CHEM & 61 & 3 & & & & & & 4 & & & \\
\hline TECTONOPHYSICS & 61 & & & & & 1 & & & & & \\
\hline J NEUROSCI RES & 60 & & 56 & & & & & 3 & 2 & & 1 \\
\hline GENE & 58 & & 3 & & & & & 12 & 40 & 6 & 1 \\
\hline PHYSICA C & 57 & & & & & & & & & & \\
\hline CLASSICAL QUANT GRAV & 56 & & & & & & & & & & \\
\hline J PARASITOL & 56 & & 6 & 25 & & 2 & & 24 & 1 & & \\
\hline SOLID STATE COMMUN & 55 & & & & & & & & & & \\
\hline BIOCHEM BIOPH RES CO & 54 & 3 & 35 & & 1 & & & 2 & 16 & & \\
\hline J HETEROCYCLIC CHEM & 54 & 54 & & & & & & & & & \\
\hline PHYS LETT B & 54 & & & & & & & & & & \\
\hline PLANT PHYSIOL & 54 & 1 & 3 & & 1 & & & 1 & 40 & 7 & \\
\hline ANAL SCl & 53 & 51 & & & & & & & & & \\
\hline J NON-CRYST SOLIDS & 53 & 1 & & & & & & & & & \\
\hline J PHYS D APPL PHYS & 51 & & & & & & & & & & \\
\hline
\end{tabular}

FUENTE: Laboratorio de Redes, Departamento de Modelación Matemática de Sistemas Sociales, IIMAS-UNAM, 2005.

Tabla 15. Artículos por revista SIC-UNAM. Área Ciencias Químico-Biológicas y de la Salud. 
REDES- Revista hispana para el análisis de redes sociales

Vol.17,\#1, diciembre 2009

http: //revista-redes.rediris.es

\begin{tabular}{|c|c|c|c|c|c|c|c|}
\hline NOMBRE DE REVISTA & Total & $\underline{\overleftarrow{ \pm}}$ & $\underline{\bar{\Xi}}$ & త্ৰ & 요 & U & $=$ \\
\hline ASTROPHYS J & 436 & 9 & & & & & \\
\hline REV MEX FIS & 397 & 1 & & 1 & & & 2 \\
\hline REV MEX ASTRON ASTR & 376 & 3 & & & & & \\
\hline ASTRON ASTROPHYS & 325 & 4 & & & & & \\
\hline PHYS REV B & 240 & & & & & & 1 \\
\hline PHYTOCHEMISTRY & 183 & & & & & & \\
\hline ABSTR PAP AM CHEM S & 161 & 3 & 2 & 3 & 3 & & 2 \\
\hline PHYS REV A & 153 & & & 1 & & & \\
\hline PHYS REV D & 152 & & & & & & \\
\hline J PHYS A-MATH GEN & 144 & & & & & & \\
\hline B SEISMOL SOC AM & 131 & 74 & 2 & & & & 66 \\
\hline ACTA CRYSTALLOGR C & 126 & & & & & & \\
\hline J CHEM PHYS & 116 & & 1 & & & & \\
\hline BACTERIOL & 115 & & & & & & \\
\hline MON NOT R ASTRON SOC & 115 & & & & & & \\
\hline PHYS REV E & 113 & & 1 & & & & \\
\hline PHYS REV C & 112 & & & & & & \\
\hline IAU SYMP & 102 & & & & & & \\
\hline PHYS REV LETT & 100 & 2 & 1 & & & & \\
\hline ASTRON J & 97 & & & & & & \\
\hline BRAIN RES & 95 & & & & & & \\
\hline PHYSICA A & 93 & & & & & & \\
\hline J MATH PHYS & 91 & & & & & & \\
\hline NUCL I NSTRUM METH B & 89 & & 1 & & & & \\
\hline REV BIOL TROP & 89 & & & 2 & & & \\
\hline THIN SOLID FILMS & 84 & & & & & & \\
\hline BIOPHYS J & 77 & & & & & & \\
\hline J NEUROCHEM & 76 & & & & & & \\
\hline PHYS LETT A & 75 & & & & & & \\
\hline FEBS LETT & 74 & & & & & & \\
\hline RADIAT PHYS CHEM & 73 & & & & & & \\
\hline SOL ENERG MAT SOL C & 70 & & & & & & 2 \\
\hline J BIOL CHEM & 67 & & & & & & \\
\hline J PHYS-CONDENS MAT & 67 & & & & & & 1 \\
\hline GEOPHYS RES LETT & 66 & 54 & 3 & 2 & & 2 & 6 \\
\hline J APPL PHYS & 66 & 1 & & & & & 1 \\
\hline J VOLCANOL GEOTH RES & 66 & 50 & 15 & & 2 & & \\
\hline MATER LETT & 66 & 1 & 1 & & & & 2 \\
\hline TOPOL APPL & 66 & & & & & & \\
\hline ARCH MED RES & 65 & & & & & & \\
\hline J ORGANOMET CHEM & 65 & & & & & & \\
\hline ASTROPHYS SPACE SCI & 64 & 6 & & & & & \\
\hline MOL PHYS & 64 & 1 & & & & & 1 \\
\hline WATER SCI TECHNOL & 64 & & 1 & & & & 59 \\
\hline CHEM PHYS LETT & 62 & & & & & & \\
\hline J NAT PROD & 62 & & & & & & \\
\hline AM J BOT & 61 & & 3 & & & & \\
\hline INT J QUANTUM CHEM & 61 & & & & & & \\
\hline TECTONOPHYSICS & 61 & 32 & 21 & & 1 & 2 & 7 \\
\hline J NEUROSCI RES & 60 & & & & & & \\
\hline GENE & 58 & & & & & & \\
\hline PHYSICA C & 57 & & & & & & \\
\hline CLASSICAL QUANT GRAV & 56 & & & & & & \\
\hline J PARASITOL & 56 & & & & & & \\
\hline SOLID STATE COMMUN & 55 & & & & & & \\
\hline BIOCHEM BIOPH RES CO & 54 & & & & & & \\
\hline J HETEROCYCLIC CHEM & 54 & & & & & & \\
\hline PHYS LETT B & 54 & & & & & & \\
\hline PLANT PHYSIOL & 54 & & & & & & \\
\hline ANAL SCl & 53 & & & & & & \\
\hline J NON-CRYST SOLIDS & 53 & & & & & & \\
\hline J PHYS D APPL PHYS & 51 & & & & & & \\
\hline
\end{tabular}

FUENTE: Laboratorio de Redes, Departamento de Modelación Matemática de Sistemas Sociales, IIMAS-UNAM, 2005

Tabla 16. Artículos por revista SIC-UNAM. Área Ciencias de la Tierra e Ingeniería. 
REDES- Revista hispana para el análisis de redes sociales

Vol.17,\#1, diciembre 2009

http: //revista-redes.rediris.es

En la Tabla 17 se muestra el total de artículos del SIC-UNAM en las revistas Nature, Science y Proceedings of the National Academy of Sciences of USA.

\begin{tabular}{|c|c|c|c|}
\hline Entidad & $\begin{array}{l}\text { Revista } \\
\text { Nature }\end{array}$ & $\begin{array}{l}\text { Revista } \\
\text { Science }\end{array}$ & $\begin{array}{c}\text { Proceedings } \\
\text { of the } \\
\text { National } \\
\text { Academy of } \\
\text { Sciences, } \\
\text { USA }\end{array}$ \\
\hline IF & 3 & 3 & \\
\hline \multicolumn{4}{|l|}{ IIM } \\
\hline ICN & 1 & 1 & \\
\hline \multicolumn{4}{|l|}{$\mathrm{ClE}$} \\
\hline \multicolumn{4}{|l|}{$\mathrm{CCF}$} \\
\hline \multicolumn{4}{|l|}{$\mathrm{CCMC}$} \\
\hline \multicolumn{4}{|l|}{ CFATA } \\
\hline \multicolumn{4}{|l|}{ IM } \\
\hline IIMAS & 1 & & 1 \\
\hline \multicolumn{4}{|l|}{ CCADET } \\
\hline IA & 10 & 3 & 1 \\
\hline \multicolumn{4}{|l|}{ CRA } \\
\hline IQ & & & 1 \\
\hline IFC & 4 & 2 & 8 \\
\hline IB & 2 & 3 & 1 \\
\hline $\mathrm{IE}$ & 3 & 8 & 5 \\
\hline ICMyL & & & 1 \\
\hline \multicolumn{4}{|l|}{ ClEco } \\
\hline IIBm & 2 & 2 & 7 \\
\hline IBt & 3 & & 9 \\
\hline CCG & 1 & 1 & 5 \\
\hline $\mathrm{INr}$ & & & 6 \\
\hline IGf & 15 & 5 & \\
\hline$|G|$ & 4 & 1 & \\
\hline CCA & & 1 & \\
\hline \multicolumn{4}{|l|}{$\mathrm{IGg}$} \\
\hline \multicolumn{4}{|l|}{ CG } \\
\hline 11 & 1 & 2 & \\
\hline $\begin{array}{c}\text { Total de } \\
\text { artículos* }\end{array}$ & 47 & 26 & 43 \\
\hline $\begin{array}{c}\text { Factor de } \\
\text { impacto } \\
\text { JCR2003 }\end{array}$ & 30.979 & 29.781 & 10.272 \\
\hline
\end{tabular}

*Sin repeticiones

Tabla 17. Artículos del SIC-UNAM en las revistas Nature, Science y Proceedings of the National Academy of Sciences, USA

En la Tabla 18 se muestra el número de revista en que han publicado artículos cada una de las entidades del SIC (valores en la diagonal), y el número de revista, en común, en que han publicado las entidades (valores fuera de la diagonal). El Instituto de Investigaciones Biomédicas es el instituto que ha publicado en un mayor número de revistas con un total de 457 . El Instituto de Física ha publicado 
REDES- Revista hispana para el análisis de redes sociales

Vol.17,\#1, diciembre 2009

http: //revista-redes.rediris.es

artículos en 422 revistas y ha publicado artículos en 160 revistas en las que el Instituto de Investigaciones en Materiales también lo ha hecho.

\begin{tabular}{|c|c|c|c|c|c|c|c|c|c|c|c|c|c|c|c|c|c|c|c|c|c|c|c|c|c|c|c|c|c|}
\hline Total & entidad & E & $\sum$ & Z & 鱼 & 정 & $\sum_{0}^{0}$ & 芯 & $\Sigma$ & $\sum_{\exists}^{\infty}$ & 己્ટુ & $\leq$ & శ్ㄱ & $\underline{g}$ & U & $\cong$ & 回 & $\sum_{0}^{2}$ & 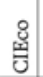 & 点 & 苗 & ర্ট & 光 & $\breve{~}$ & త్ & తુర & $\mathscr{0}^{\infty}$ & 8 & $=$ \\
\hline 422 & IF & 422 & 160 & 123 & 46 & 75 & 78 & 28 & 41 & 48 & 61 & 34 & 2 & 84 & 29 & 13 & 14 & 8 & 1 & 27 & 18 & 8 & 8 & 39 & 18 & 14 & 6 & 4 & 29 \\
\hline 282 & IIM & 160 & 282 & 61 & 54 & 38 & 54 & 23 & 17 & 18 & 44 & 16 & & 66 & 13 & 7 & 4 & 5 & & 10 & 6 & 1 & 1 & 20 & 11 & 9 & 2 & & 24 \\
\hline 194 & ICN & 123 & 61 & 194 & 23 & 44 & 26 & 11 & 33 & 38 & 29 & 36 & 2 & 45 & 8 & 6 & 6 & 5 & & 10 & 7 & 5 & 1 & 33 & 11 & 11 & 1 & 2 & 13 \\
\hline 109 & CIE & 46 & 54 & 23 & 109 & 20 & 25 & 6 & 9 & 7 & 22 & 8 & & 19 & 1 & 2 & 3 & 4 & & 3 & 6 & & 1 & 21 & 15 & 2 & 4 & 5 & 20 \\
\hline 91 & CCF & 75 & 38 & 44 & 20 & 91 & 23 & 12 & 22 & 22 & 20 & 14 & 2 & 27 & 7 & 1 & 3 & 2 & & 8 & 5 & 2 & 2 & 10 & 8 & 3 & 2 & & 8 \\
\hline 94 & $\mathrm{CCMC}$ & 78 & 54 & 26 & 25 & 23 & 94 & 14 & 15 & 11 & 26 & 15 & & 19 & 4 & 2 & & 3 & & 4 & 1 & 1 & 1 & 7 & 6 & 2 & 1 & 1 & 10 \\
\hline 35 & CFATA & 28 & 23 & 11 & 6 & 12 & 14 & 35 & 8 & 5 & 9 & 5 & & 8 & & 1 & & 1 & & 1 & & & 1 & 3 & 2 & 1 & & & 2 \\
\hline 178 & IM & 41 & 17 & 33 & 9 & 22 & 15 & 8 & 178 & 55 & 12 & 10 & & 15 & 7 & 2 & 3 & 3 & & 7 & 6 & 3 & 4 & 11 & 6 & 7 & 1 & & 5 \\
\hline 237 & IIMAS & 48 & 18 & 38 & 7 & 22 & \begin{tabular}{|l|}
11 \\
\end{tabular} & 5 & 55 & 237 & 16 & 14 & & 15 & 12 & 13 & 13 & 7 & & 19 & 11 & 8 & 7 & 22 & 9 & 12 & 6 & 2 & 20 \\
\hline 128 & CCADET & 61 & 44 & 29 & 22 & 20 & 26 & 9 & 12 & 16 & 128 & 16 & 2 & 22 & 19 & 6 & 8 & 7 & & 20 & 17 & 4 & 9 & 12 & 3 & 8 & 2 & 1 & 20 \\
\hline 76 & IA & 34 & 16 & 36 & 8 & 14 & 15 & 5 & 10 & 14 & 16 & 76 & 2 & 8 & 4 & 3 & 5 & 3 & & 6 & 4 & 4 & 3 & 21 & 7 & 5 & & & 10 \\
\hline 3 & CRA & 2 & & 2 & & 2 & & & & & 2 & 2 & 3 & & & & & & & & & & & 2 & & & & & \\
\hline 288 & IQ & 84 & 66 & 45 & 19 & 27 & 19 & 8 & 15 & 15 & 22 & 8 & & 288 & 47 & 33 & 22 & 14 & & 50 & 41 & 15 & 15 & 6 & 7 & 10 & 4 & & 5 \\
\hline 324 & IFC & 29 & 13 & 8 & 1 & 7 & 4 & & 7 & 12 & 19 & 4 & & 47 & 324 & 28 & 26 & 15 & 1 & 156 & 112 & 35 & 66 & 4 & 8 & 12 & 4 & 1 & 4 \\
\hline 250 & IB & 13 & 7 & 6 & 2 & 1 & 2 & 1 & 2 & 13 & 6 & 3 & & 33 & 28 & 250 & 90 & 49 & 6 & 40 & 26 & 15 & 9 & 13 & 20 & 18 & 9 & & 7 \\
\hline 230 & IE & 14 & 4 & 6 & 3 & 3 & & & 3 & 13 & 8 & 5 & & 22 & 26 & 90 & 230 & 33 & 10 & 35 & 32 & 24 & 9 & 16 & 19 & 16 & 24 & 1 & 15 \\
\hline 161 & ICMyL & 8 & 5 & 5 & 4 & 2 & 3 & 1 & 3 & 7 & 7 & 3 & & 14 & 15 & 49 & 33 & 161 & & 20 & 17 & 10 & 10 & 24 & 23 & 16 & 10 & 3 & 13 \\
\hline 10 & CIEco & 1 & & & & & & & & & & & & & 1 & 6 & 10 & & 10 & & 3 & & & & 1 & & 1 & & \\
\hline 457 & IIBm & 27 & 10 & 10 & 3 & 8 & 4 & 1 & 7 & 19 & 20 & 6 & & 50 & 156 & 40 & 35 & 20 & & 457 & 116 & 37 & 67 & 9 & 5 & 19 & 1 & & 7 \\
\hline 278 & IBt & 18 & 6 & 7 & 6 & 5 & 1 & & 6 & 11 & 17 & 4 & & 41 & 112 & 26 & 32 & 17 & 3 & 116 & 278 & 48 & 39 & 3 & 7 & 7 & 3 & 1 & 14 \\
\hline 90 & CCG & 8 & 1 & 5 & & 2 & 1 & & 3 & 8 & 4 & 4 & & 15 & 35 & 15 & 24 & 10 & & 37 & 48 & 90 & 7 & 3 & 3 & 2 & 1 & & 4 \\
\hline 120 & $\mathrm{INr}$ & 8 & 1 & 1 & 1 & 2 & 1 & 1 & 4 & 7 & 9 & 3 & & 15 & 66 & 9 & 9 & 10 & & 67 & 39 & 7 & 120 & 1 & & 4 & & & 1 \\
\hline 161 & IGf & 39 & 20 & 33 & 21 & 10 & 7 & 3 & 11 & 22 & 12 & 21 & 2 & 6 & 4 & 13 & 16 & 24 & & 9 & 3 & 3 & 1 & 161 & 58 & 26 & 20 & 18 & 34 \\
\hline 129 & IGl & 18 & 11 & 11 & 15 & 8 & 6 & 2 & 6 & 9 & 3 & 7 & & 7 & 8 & 20 & 19 & 23 & 1 & 5 & 7 & 3 & & 58 & 129 & 9 & 16 & 17 & 20 \\
\hline 83 & $\mathrm{CCA}$ & 14 & 9 & 11 & 2 & 3 & 2 & 1 & 7 & 12 & 8 & 5 & & 10 & 12 & 18 & 16 & 16 & & 19 & 7 & 2 & 4 & 26 & 9 & 83 & 10 & 2 & 12 \\
\hline 62 & IGg & 6 & 2 & 1 & 4 & 2 & 1 & & 1 & 6 & 2 & & & 4 & 4 & 9 & 24 & 10 & 1 & 1 & 3 & 1 & & 20 & 16 & 10 & 62 & 6 & 8 \\
\hline 20 & CG & 4 & & 2 & 5 & & 1 & & & 2 & 1 & & & & 1 & & 1 & 3 & & & 1 & & & 18 & 17 & 2 & 6 & 20 & 7 \\
\hline 170 & II & 29 & 24 & 13 & 20 & 8 & 10 & 2 & 5 & 20 & 20 & 10 & & 5 & 4 & 7 & 15 & 13 & & 7 & 14 & 4 & 1 & 34 & 20 & 12 & 8 & 7 & 170 \\
\hline
\end{tabular}

FUENTE: Laboratorio de Redes, Departamento de Modelación Matemática de Sistemas Sociales, IIMAS-UNAM, 2005.

Tabla 18. Número de revistas en que se han publicado artículos del SIC.

En la Tabla 19 se muestra el promedio de artículos por revistas para cada una de las entidades del subsistema.

\begin{tabular}{|l|r|}
\hline Entidad & Promedio \\
\hline IA & 22.58 \\
\hline $\mathrm{IF}$ & 7.19 \\
\hline $\mathrm{ICN}$ & 6 \\
\hline $\mathrm{IIM}$ & 4.78 \\
\hline $\mathrm{IM}$ & 4.04 \\
\hline $\mathrm{CIE}$ & 3.52 \\
\hline $\mathrm{CCF}$ & 3.12 \\
\hline CCMC & 2.99 \\
\hline $\mathrm{IIMAS}$ & 2.17 \\
\hline CCADET & 2.11 \\
\hline CRA & 2 \\
\hline CFATA & 1.49 \\
\hline
\end{tabular}

\begin{tabular}{|l|r|}
\hline Entidad & Promedio \\
\hline $\mathrm{IQ}$ & 6.36 \\
\hline $\mathrm{IFC}$ & 4.52 \\
\hline $\mathrm{IB}$ & 3.93 \\
\hline $\mathrm{ICMyL}$ & 3.8 \\
\hline $\mathrm{IBt}$ & 3.73 \\
\hline $\mathrm{CCG}$ & 3.33 \\
\hline $\mathrm{IE}$ & 3.13 \\
\hline $\mathrm{IIBm}$ & 3 \\
\hline $\mathrm{INr}$ & 2.28 \\
\hline $\mathrm{CIECO}$ & 1.1 \\
\hline
\end{tabular}

\begin{tabular}{|l|r|}
\hline Entidad & Promedio \\
\hline $\mathrm{IGf}$ & 5.04 \\
\hline $\mathrm{II}$ & 3.04 \\
\hline $\mathrm{IGI}$ & 2.84 \\
\hline $\mathrm{CCA}$ & 2.83 \\
\hline $\mathrm{CG}$ & 2.05 \\
\hline $\mathrm{IGg}$ & 1.47 \\
\hline
\end{tabular}

FUENTE: Laboratorio de Redes, Departamento de Modelación Matemática de Sistemas Sociales, IIMAS-UNAM, 2005

Tabla 19. Promedio de artículos por revista SIC. 
REDES- Revista hispana para el análisis de redes sociales

Vol.17,\#1, diciembre 2009

http: //revista-redes.rediris.es

\section{Citas por artículo}

El número promedio de citas por artículo de los artículos de investigadores afiliados a entidades del SIC es de 6.10. En la Tabla 20 se muestra los valores para las todas las entidades del SIC.

\begin{tabular}{|l|r|r|r|l|l|r|r|r|}
\hline Entidad & $\begin{array}{r}\text { Total de } \\
\text { Artículos }\end{array}$ & $\begin{array}{c}\text { Total de } \\
\text { Citas }\end{array}$ & $\begin{array}{c}\text { Total de } \\
\text { Citas / } \\
\text { Total de } \\
\text { Artículos }\end{array}$ & & Entidad & $\begin{array}{c}\text { Total de } \\
\text { Artículos }\end{array}$ & $\begin{array}{c}\text { Total } \\
\text { de } \\
\text { Citas }\end{array}$ & $\begin{array}{l}\text { Total de } \\
\text { Citas / } \\
\text { Total de } \\
\text { Artículos }\end{array}$ \\
\hline IF & 3034 & 23392 & 7.71 & & IB & 983 & 5273 & 5.36 \\
\hline IIM & 1347 & 6787 & 5.04 & & IE & 719 & 7810 & 10.86 \\
\hline ICN & 1164 & 6581 & 5.65 & & ICMyL & 611 & 2885 & 4.72 \\
\hline CIE & 384 & 1088 & 2.83 & & CIECO & 11 & 8 & 0.73 \\
\hline CCF & 284 & 919 & 3.24 & & II Bm & 1369 & 13651 & 9.97 \\
\hline CCMC & 281 & 629 & 2.24 & & I Bt & 1037 & 11527 & 11.12 \\
\hline CFATA & 52 & 41 & 0.79 & & CCG & 300 & 7928 & 26.43 \\
\hline IM & 720 & 1919 & 2.67 & & INr & 274 & 1347 & 4.92 \\
\hline IIMAS & 514 & 2554 & 4.97 & & IGf & 811 & 5872 & 7.24 \\
\hline CCADET & 270 & 856 & 3.17 & & IGI & 367 & 2252 & 6.14 \\
\hline IA & 1716 & 22278 & 12.98 & & CCA & 235 & 1385 & 5.89 \\
\hline CRA & 6 & 4 & 0.67 & & IGg & 91 & 210 & 2.31 \\
\hline IQ & 1832 & 9563 & 5.22 & & CG & 41 & 15 & 0.37 \\
\hline IFC & 1463 & 17676 & 12.08 & & II & 517 & 2899 & 5.61 \\
\hline
\end{tabular}

FUENTE: Laboratorio de Redes, Departamento de Modelación Matemática de Sistemas Sociales, IIMAS-UNAM, 2005.

Tabla 20. Artículos, citas y citas por artículo SIC-UNAM. 


\section{Resumen, Conclusiones y Trabajo futuro \\ Resumen}

En este trabajo presentamos el análisis de la estructura de las colaboraciones de científicos en los campos del conocimiento que se cultivan México, la UNAM y el Subsistema de la Investigación Científica; en cada artículo indizado por Thomson Scientific (antes ISI Thomson) hay por lo menos un autor de México. Hemos presentado una visión general de las redes de académicos a través de sus publicaciones: determinamos como se agrupan las diversas entidades académicas, en que revistas publican, los coautores de instituciones nacionales e internacionales; en que revistas publican; en que áreas, entre otros.

Determinamos que el número promedio de citas de todos los campos es 4.64 por artículo, en una ventana de tiempo que va de 1993 a 2003. La publicación de artículos, incluyendo coautores, se encuentra en la región 50 a 10000 artículos 500 a 30000 citas. Garfield menciona la importancia del uso de indicadores cuantitativos para evaluar las políticas de desarrollo de la Ciencia y de la Tecnología.

Pocos podrán discutir la propuesta de que la base científica y tecnológica es un elemento crítico en la fortaleza de la economía, de la estatura política y de la vitalidad cultural de un país. Los administradores del gobierno, los creadores de las políticas de ciencia y tecnología y los directivos de las universidades requieren de indicadores validos y confiables para una variedad de propósitos: por ejemplo, para medir la efectividad del gasto en investigación, identificar las áreas de excelencia, para fijar prioridades en su planeación estratégica, monitorear el avance de sus competidores y de sus colegas, y detectar especialidades emergentes y nuevas tecnologías para lograr un desarrollo acelerado y de la necesidad de contar con elementos para medir estos indicadores.

El número total de artículos indizados por ISI-Thomson con participación de investigadores afiliados a instituciones mexicanas, en el periodo bajo estudio, es de 71868. La UNAM participa en casi el 38\% de la producción de los artículos, el otro $62 \%$ lo realizan diversas instituciones, como lo mostramos en la Figura 2. 
REDES- Revista hispana para el análisis de redes sociales

Vol.17,\#1, diciembre 2009

http: //revista-redes.rediris.es

Publicación anual de artículos

La publicación anual de artículos en el ámbito nacional presenta un incremento notorio y constante a partir del año de 1990, de acuerdo con la Gráfica 3, como resultado de las políticas de Ciencia y Tecnología de años recientes, antes de 1990 la tasa de crecimiento anual promedio nacional de artículos era de $2.9 \%$, la de la UNAM de $6 \%$ y la de otras instituciones sin incluir a la UNAM del $1.22 \%$. Del año de 1990 al 2001 la tasa de crecimiento anual promedio nacional fue de $15 \%$, la de la UNAM del $10 \%$ y la de las diversas instituciones sin incluir a la UNAM de $11.6 \%$, lo que marca un despunte en la producción de artículos de otras entidades nacionales. Los artículos con dos autores sobrepasan a los de un autor desde 1984, los de tres autores sobrepasan a los de un autor desde 1984. El caso de cuatro autores ocurre desde 1993. El caso de tres a dos autores ocurre en 1995, y el de cuatro a uno también ocurre en 1995. En 2003 el orden es 3, 2, 4, 5, 6, 1 autores por artículo.

Los investigadores afiliados a Instituciones Nacionales que se localizan en Distrito Federal y en los estados de Morelos, Puebla, Guanajuato y Estado de México, son autores o coautores de $57161^{14}$ de un total de 71868 artículos, lo que representa cerca del $80 \%$. Los investigadores afiliados a Instituciones Nacionales que se localizan en Distrito Federal y en los estados de Morelos, Puebla, Baja California, Guanajuato, Jalisco y Nuevo León, son autores o coautores de 62164 de un total de 71868 artículos, lo que representa más del $86 \%$. Estas entidades tienen un total superior a 2000 artículos. Determinamos que la publicación de artículos científicos de la UNAM, el Subsistema de la Investigación Científica contribuyo con el 75.6 \% y el Subsistema de Escuelas y Facultades con el $28.8 \%$, Gráfica 6.

\section{Colaboración entre subsistemas}

Las entidades de la UNAM escribieron 2981 artículos en colaboración con otras entidades de la UNAM lo que representa un $11.8 \%$ de colaboración entre entidades. Las entidades de la UNAM escribieron 1583 artículos en colaboración con otras entidades del otro subsistema, que representa el $8.3 \%$ de artículos en colaboración entre subsistemas.

Publicaciones

La entidad que participó en el mayor número de artículos fue el Instituto de Física con un total de 3040. En la Gráfica 8 se muestra el total de artículos por entidad. Las entidades están agrupadas por área de conocimiento: Ciencias Físico

\footnotetext{
${ }^{14}$ Estas cifras corresponde al total acumulado de dichos Estados.
} 
REDES- Revista hispana para el análisis de redes sociales

Vol.17,\#1, diciembre 2009

http: //revista-redes.rediris.es

Matemáticas (amarillo), Ciencias Químico-Biológicas y de la Salud (azul) y Ciencias de la Tierra e Ingenierías (verde).

Colaboración con instituciones del extranjero

Encontramos que los investigadores afiliados a entidades del Subsistema de la Investigación Científica de la UNAM han colaborado con investigadores afiliados a 2405 Instituciones de 103 países diferentes. En la Gráfica 12 mostramos 30 países con que se ha colaborado con más de 50 artículos.

El $6.2 \%$ de los artículos (566) publicados por el área de las Ciencias Físico Matemáticas, CFM, Figura 5, corresponden a aquellos que se encuentran fuera de la diagonal de la Tabla 8 y sin repeticiones. En el mismo caso se encuentran las Ciencias Químico Biológicas y de la Salud, CQBS con un 4.4\% (262 artículos), finalmente en el caso de Ciencias de la Tierra y de las Ingenierías, CTI, el $5.9 \%$ de los artículos (114) es el que se encuentra fuera de la diagonal El total de artículos escritos en colaboración entre las tres áreas es de 255 y representa el $1.33 \%$ del total.

\section{Artículos por área}

En la Tabla 9 mostramos el total de artículos de las diversas entidades que pertenecen al SIC, por área de conocimiento,. Cabe señalar que el mayor número de artículos se escriben en el área de Physical, Chemical \& Earth Sciences.

En la Tablas 10, 11 y 12 se muestra el total de artículos por área de conocimiento, y su distribución por cada una de las entidades que pertenecen al SIC. Cabe señalar que el mayor número de artículos se escriben en el área de Physical, Chemical \& Earth Sciences.

Artículos por Revista

Encontramos que los investigadores de las entidades académicas pertenecientes al SIC y han escrito artículos en 2387 revistas. En la Tabla 13 se muestra, por área, el número de revistas donde han sido publicados los artículos de los investigadores afiliados a entidades del SIC, hay revistas que están clasificados en más de un área.

Determinamos el número de artículos que han publicado las entidades listadas en la Tabla 17 en las revistas Nature, Science y en los Proceedings de la Academia Nacional de Ciencias de los Estados Unidos de Norteamérica.

Un dato interesante y que refleja el interés de los investigadores en publicar en un grupo escogido de revistas que se adaptan a su perfil académico, es el siguiente: 
REDES- Revista hispana para el análisis de redes sociales

Vol.17, \#1, diciembre 2009

http: //revista-redes.rediris.es

El Instituto de Astronomía ha publicado 22.58 artículos por revista en promedio, el Instituto de Física 7.19, el Instituto de Química 6.36 y el de Geofísica 5.04.

\section{Conclusiones}

Este trabajo nos ha permitido abrir una ventana en el tiempo y observar como se ha desarrollado el proceso de investigación científica en nuestro país y en particular en la Universidad Nacional Autónoma de México y del Subsistema de la Investigación Científica.

Hemos examinado el crecimiento de la publicación de artículos científicos de 1981 a 2003; en México, la UNAM y el SIC. Determinamos cuales son las entidades académicas que han publicado conjuntamente, en que áreas, en que revistas y con que intensidad. Para cada entidad determinamos el número de artículos, en que áreas y en que revistas de tal suerte que tenemos un mapa de todas las interacciones: publicaciones entre entidades, con otros países, determinación de instituciones extranjeras, áreas y número de artículos. Podemos decir que tenemos la caracterización de toda la estructura de comunicación de gentes e instituciones.

Deberemos hacer un análisis cuidadoso y sistemático cuyos resultados sirvan a las autoridades de Ciencia y Tecnología del Gobierno Central y de los Estados para tomas decisiones que impulsen el desarrollo de la investigación y desarrollo tecnológico a otro estadio. Deberemos escalar en la tabla de los países pertenecientes a la OCDE.

\section{Trabajo futuro}

Tenemos una tarea muy importante a futuro que consiste en determinar las redes de cada uno de los académicos del Subsistema de la Investigación Científica, en esta búsqueda deberán quedar registrados estudiantes que estén realizando sus tesis de licenciatura, maestría o doctorado su participación en proyectos de investigación (PAPIIT, CONACYT, otros), identificación de coautores extranjeros y determinación de grupos de pertenencia. Explicar como se ha dado el desarrollo de cada entidad académica, cuales son los factores que han influido mas en su desarrollo. Tratar de determinar en que lugar de la arena nacional e internacional se localiza cada una de las entidades del subsistema de la investigación científica. Será importante comparar nuestro indicadores con los de otros países; los cercanos y los que se encuentran en los primeros lugares. ¿Que deberemos hacer para impulsar la Ciencia y Tecnología de nuestro país para que pase al siguiente nivel? Esta es una pregunta que proponemos a los expertos en el tema. 
REDES- Revista hispana para el análisis de redes sociales

Vol.17,\#1, diciembre 2009

http: // revista-redes.rediris.es

\section{Bibliografía}

De Solla Price, D. J. (1963). Little Science, Big Science, Columbia University Press, New York.

Garfield, E. (Chairman Emeritus, ISI) (2004). Systematic Serendipity: Finding the Undiscovered Answers to Science Questions, The Medical Ignorance Collaboratory University of Arizona Health Science Center, Tucson, Arizona, USA, July.

Garfield, E. (1996). “When to cite”, Library Quarterly, Vol. 66 (4), p.449-458, October.

Garfield, E. and Welljams-Dorof, A. (1992). "Citation data: their use as quantitative indicators for science and technology evaluation and policy-making", Science \& Public Policy, 19(5) pp.321-327, October.

J. Sylvan Katz and Ben R. Martin (1997), "What is research collaboration?", Research Policy, 26: 1-18.

M.E.J. Newman (2001), "The Structure of Scientific collaboration Networks", PNAS, January, 98(2):404-409.

Jane M. Russell (2005), "Scientific Communication at the Beginning of the TwentyFirst Century", Proceedings of the American Society for Information Science and Technology, 41(1): 545 - 549.

Smith, M. (1958). "The trend toward multiple authorship in Psychology", American Psychologist 13, 596-599. 